Western University

Scholarship@Western

Business Publications

Business (Richard Ivey School of Business)

2017

\title{
Discrete event simulation model for planning Level 2 "step-down" bed needs using NEMS
}

Felipe F. Rodrigues

Ivey Business School at Western University, frodrigues.phd@ivey.ca

Gregory S. Zaric

University of Western Ontario

David Stanford

Western University

Follow this and additional works at: https://ir.lib.uwo.ca/iveypub

Part of the Business Administration, Management, and Operations Commons, Health and Medical Administration Commons, Health Services Administration Commons, and the Management Sciences and Quantitative Methods Commons

Citation of this paper:

F. Rodrigues, G.S. Zaric, D.A. Stanford, Discrete event simulation model for planning Level 2 "step-down" bed needs using NEMS, In Operations Research for Health Care, 2017, ISSN 2211-6923, https://doi.org/10.1016/j.orhc.2017.10.001. 


\section{Discrete event simulation model for planning Level 2 "step-down" bed needs using NEMS}

F.Rodrigues, G.S.Zaric, D.A.Stanford

This is the peer reviewed version of the following article: F. Rodrigues, G.S. Zaric, D.A. Stanford, Discrete event simulation model for planning Level 2 "step-down" bed needs using NEMS, In Operations Research for Health Care, 2017, which has been published in final form at https://doi.org/10.1016/i.orhc.2017.10.001. This article may be used for non-commercial purposes in accordance with Elsevier's Terms and Conditions for Self-Archiving." 


\title{
Discrete event simulation model for planning Level 2

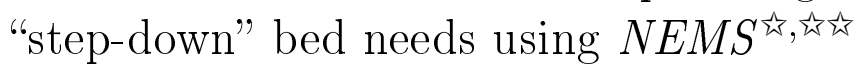

\author{
F. Rodrigues ${ }^{\mathrm{a}, *}$, G. S. Zaric ${ }^{\mathrm{a}}$, D. A. Stanford ${ }^{\mathrm{b}}$ \\ ${ }^{a}$ Ivey Business School at Western University, London, Ontario, N6G oN1, Canada \\ ${ }^{b}$ Statistical 83 Actuarial Sciences at Western University, London, Ontario, N6A $3 K^{7}$, \\ Canada
}

\begin{abstract}
In highly congested hospitals it may be common for patients to overstay at Intensive Care Units (ICU) due to blockages and imbalances in capacity. This is inadequate clinically, as patients occupy a service they no longer need; operationally, as it disrupts flow from upstream units; and financially as ICU beds are more expensive than ward beds. Step-down beds, also known as Level 2 beds, have become an increasingly popular and less expensive alternative to ICU beds to deal with this issue. We developed a discrete event simulation model that estimates Level 2 bed needs for a large university hospital. The model innovates by simulating the entirety of the hospital's inpatient flow and most importantly, the ICU's daily stochastic flows based on a nursing workload scoring metrics called "Nine Equivalents of Nursing Manpower Use Score" (NEMS). Using data from a large academic hospital, the model shows the benefits of Level 2 beds in improving both patient flow and costs.
\end{abstract}

\footnotetext{
This work was supported by: The Ontario Trillium Scholarship program (OTS); The Ivey International Centre for Health Innovation (IICHI); Natural Sciences and Engineering Research Council of Canada (NSERC), and the Universidade Federal do Parana (UFPR). These funding sources had no active role in the study design, collection, analysis, interpretation of data, writing of the report or decision to submit the article for publication. This research is approved by Western University's and LHSC's Research Ethics Board under the file \# REB 105583.

We would like to acknowledge the contribution of the following: J. Kojlak, Dr. C. Martin and F. Priestap from London Health Sciences Center, London, Ontario, N6A 5W9, Canada

${ }^{*}$ Corresponding author

Email address: frodrigues@ivey.ca (F. Rodrigues)
} 
Keywords: bed capacity planning, patient flow, step-down beds, Level 2 beds, discrete-event simulation, NEMS

2008 MSC: 68M20 Performance evaluation; queuing; scheduling, 90B15

Network models, 90B22 Queues and service, 90B90 Case-oriented studies, 91B70 Stochastic models, 91B74 Models of real-world systems

\section{1. Introduction}

2 Contemporary hospitals in developed countries strive to provide the best

3 possible patient care while keeping costs at reasonable levels (Doig [12], Batche-

4 lor [6], Hoyt [20]). Hospital beds are too costly to remain idle, while insufficient

5 beds can be detrimental to in patient care (Harper [18]). Critical care in par-

6 ticular is very expensive: in the USA and Canada, ward beds cost as much

7 as $\$ 1,000 /$ day while critical care beds surpass $\$ 3,500 /$ day (Noseworthy et al.

s [36], Halpern and Pastores [17]).

9 The University Hospital (UH) campus of the London Health Sciences Cen-

10 tre (LHSC) is a 400 bed hospital responsible for approximately 6,200 surgeries,

1160,000 emergency visits, 300,000 ambulatory visits and 17,000 inpatient admis-

12 sions per year (LHSC [29]). It routinely experiences bed utilization rates above

$1385 \%$ which are high compared to the North American average of $67.6 \%$ for com-

14 parable sized hospitals (NCHS [34]). When the wards at UH become congested

15 there is pressure on the Medical-Surgical Intensive care unit (MSICU) to take

16 one of two actions: hold some patients in ICU longer than they care ("overstay"),

17 or transfer some patients to a ward other than their intended one ("off-service").

18 Overstay creates a ripple effect in upstream units such as the Operating Room

19 (OR) and the Emergency Department (ED), resulting in a disruption in pa-

2o tient flow upstream, delayed surgeries and lengthy ED visits. Off-service is

${ }_{21}$ sub-optimal clinically because of staff specialization, such as intensivist nurses 
34 if such unit were to be employed.

35 This research assesses the impact of step-down beds on a number of hospital 39 by the NEMS. We address the following research questions:

40

41

and physicians. Off-service is also sub-optimal operationally because specialist doctors must visit different wards to see their patients, creating delays and coordination issues. Thus, off-service treatment should be avoided whenever possible (Shukla et al. [45]). LHSC estimates that up to $30 \%$ of patients at in the specialized Multi-Organ Transplant unit are off-service patients.

To improve patient flow, provide adequate care and reduce costs, UH intends to implement an intermediary care unit between the MSICU and its downstream wards, called "step-down" or, "Level 2" unit (L2). These wards usually do not support ventilation, but they can still provide some organ support (see Table 1). They are less costly in technology and in the patient/nurse ratio, typically two patients per nurse rather than one-on-one found in ICU. Among UH's primary concerns is the determination of the ideal capacity a new L2 unit should have metrics including throughput, length of stay (LOS), " off-service" and cost. We develop a DES model to analyze a hospital's L2 bed needs that incorporates the changes in ICU patient health through time, where patient health is modeled

1. What is the impact of a L2 unit on throughput, off-service, inpatient LOS and cost?

2. What is the optimal allocation of MSICU and Level 2 beds for UH?

\section{Literature Review}

\subsection{Research streams}

There ares two main streams of literature related to bed capacity management and planning: queuing models and discrete-event simulation (DES) models 


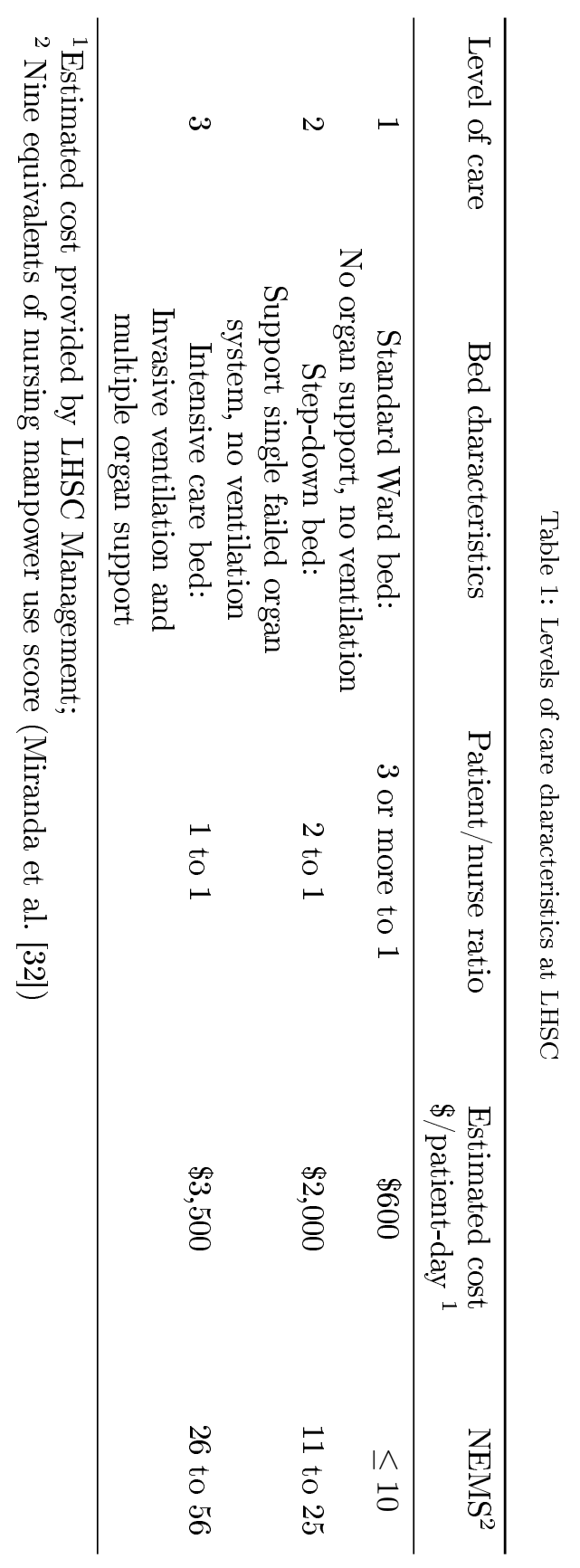


47 (Bountourelis et al. [7]). Queuing models range from analytical queuing method-

48 ology such as the use of the $M / M / 1$ (Green [15]) and Erlang loss models (Green

49 et al. [16], Rau et al. [38]) to the use of complex network models (Osorio and

5o Bierlaire [37], Bretthauer et al. [9], Noghani Ardestani [35], Zonderland et al.

51 [47]). Green [15] presents a survey of this stream of literature, and taxonomies

52 have been devised by Mielczarek and Uzialko-Mydlikowska [31], Lakshmi C.

${ }_{53}[26]$, Bountourelis et al. [7].

${ }_{54}$ 2.2. Discrete Event Simulation in Health Care Capacity Management

55 DES is a popular alternative to queuing models because it is possible to

56 study applications with large scale and scope and to relax many of the assump-

57 tions necessary in queuing models. The DES literature most often focuses on

58 a single unit of a hospital (e.g. ED, OR) and/or on a single type of patients

59 (e.g. trauma, surgery, cardiac). Research is usually focused on designing a new

6o patient flow strategy (early transfers, faster service, better schedules) often in

61 combination with structural improvements, such as pooling, or increased capac-

62 ity. For example, Harper [18] tested pooling respiratory patients into a single

${ }_{63}$ unit similar to a L2 unit. Harper [18] found pooling to show significant improve-

64 ments in patient throughput and flow balance. Rohleder et al. [40], Rau et al.

${ }_{65}^{65}[38]$ share those findings, but stress that pooling patients seems to be partic-

66 ularly beneficial in high variance service time settings such as ICU's. Shahani

67 et al. [44] simulate a high dependency unit (HDU) and they found that pooling

68 alone only managed to reduce transfers/off-service but kept similar through-

69 put and utilization levels. They could only achieve better results when pooling

7o was combined with earlier stepping-down of long stay patients. Van Berkel

71 and Blake [46] found that capacity increase alone is not enough to stabilize

72 OR patient flows, often requiring faster service times as well. Comparable re-

73 sults are found by Duguay and Chetouane [13], Khare et al. [23], Konrad et al. 

[25] in emergency department settings. Ridge et al. [39], Kolker [24], Marmor

75 et al. [30] investigated congestion by smoothing surgery schedules, which en76 abled performance gains in ICU utilization, LOS and off-service. Seung-Chul 77 et al. [43], Dobson et al. [11], Anderson et al. [4, 3], $\mathrm{KC}$ and Terwiesch [22] 78 suggest that highly congested health care systems may trigger other responses 79 such as early discharges/transfers/off-service - in order to accommodate higher so demands, often with negative results.

81 2.3. Contributions of this paper

82 Our model attempts to correctly represent the complex flow and interac83 tions present in modern general hospitals without some of the simplifications

s4 found in the literature. Our DES model includes "bounce-backs" (patients be85 ing transferred back from wards to units upstream), overstay and off-service s6 endogenously. In other words, those phenomena are consequences of congestion ${ }_{87}$ as opposed to exogenous parameters of the simulation. Thus, we are able to ${ }_{88}$ observe congestion and the impact of changes in capacity and bed mix on cons9 gestion. We find a clear trade-off between added capacity and changes in bed so mix that might otherwise be absent in previous models due to simplifying as91 sumptions. A model that does not include all these characteristics may provide 92 little help in capacity planning problems.

93 In addition, we include in the ICU simulation the patient's daily health ${ }_{94}$ changes in the form of a death/NEMS scoring routine. This stochastic process 95 provides a precise, realistic simulation of an ICU patient and endogenously 96 creates reliable LOS for bed capacity purposes. 
97

98 3.1. Initial Steps

99 The first step of the research was to meet with several managers at LHSC to 100 understand the problem and agree upon stakeholder involvement as suggested 101 by Brailsford et al. [8]. The research objective was defined during the first three

\section{Materials and Methods} exploratory meetings and validated after an initial research proposal draft was presented. The research proposal was reviewed and approved by ethics boards of LHSC and Western University. Management at LHSC were highly involved with the research, periodically revising goals and methods and validating each step to ensure meaningful and actionable results.

\subsection{Model Overview}

We built the DES model using the software package Simul8@. This software was chosen for three main reasons. First, it has become a popular choice in the healthcare DES literature (Almashrafi and Vanderbloemen [2], Mohiuddin et al. [33], Salleh et al. [41]). Secondly, its ease of coding allows for flexible modeling, and it features a graphical interface that plays an important role in conveying results to multiple stakeholders. Thirdly, and because of the former two, our institution has experience in using this software for healthcare DES research.

We built the model representing the current capacity allocation of UH as a baseline scenario (Figure 1; for a detailed model, see A.10). There are six entry points for inpatients: Emergency Department (ED), Operating Room (OR), Clinics, Victoria Hospital (the other major hospital in the LHSC system), OneConsult (inpatient transfers from other hospitals outside of the LHSC system), ADT (Admission/Discharge/Transfer). ADT is is a mock entry point the hospital uses to temporarily admit patients while they are not assigned a bed in a ward. Each entry point has its own inter-arrival time distributions 


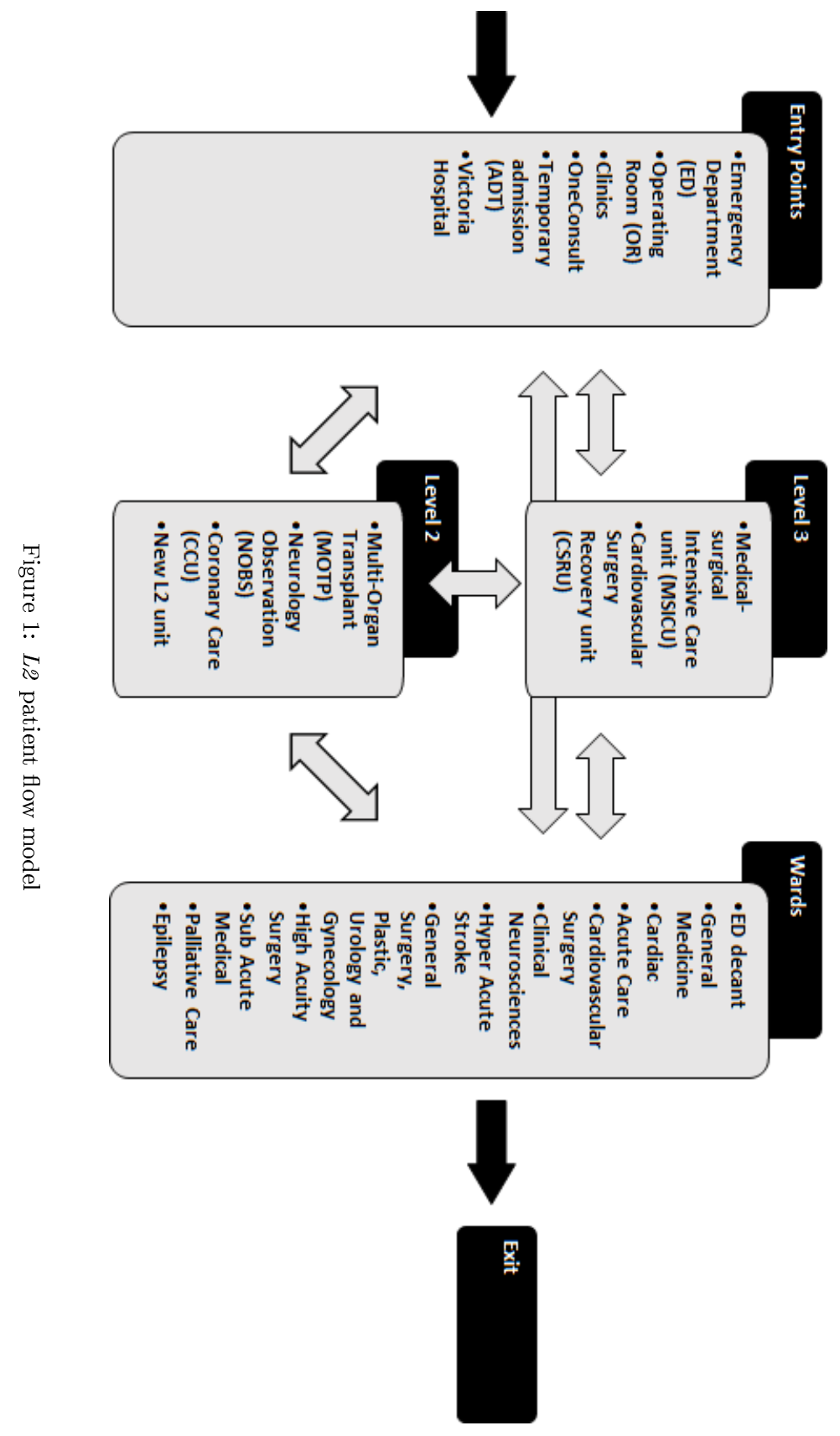



(see AppendixA). Inpatients flow from the entry points to the remaining units. There are two independent Level 3 units (MSICU and Cardiac-Surgical Intensive Care Unit (CSRU), three existing Level 2 units (tailored to other specific patient groups) and twelve specialized wards (Table A.8). Patients exit the hospital via three routes: Discharge, "Signed Out", or Death.

Since the level of care is closely related to patient/nurse ratio, LHSC has historically used nursing workload as a proxy for patient readiness to step down to a lower level of care. As part of the MSICU's routine, every patient is scored daily in a 56 point scale known as "Nine equivalents of nursing manpower use score" or "NEMS" (Miranda et al. [32]). The NEMS gives a measurement of the workload a nurse has for each patient over time and is closely related to patient health because as the patient's health improves, less nursing attention is needed, resulting in a lower NEMS. Empirically, LHSC considers a score below 10 to be a "Ward type" patient; scores between 11-25 would be "L2 type" patient, and from 26-56 an "ICU type" patient (see Table 1).

\subsection{Patient Flow Data}

The model was fit using the most recent one year of data in which UH's bed allocation was stable (i.e., same number of beds in all units over the entire year), from December $1^{\text {st }} 2013$ to November $30^{\text {th }} 2014$. Data was gathered from the hospital's patient management system, including:

1. Inpatient arrivals: patient registry number, age, sex, diagnosis, entry point, exit point, service at arrival, service at discharge, discharge category (discharge, death, transfer), dates and time of arrival and of discharge.

2. Inpatient Transfers: all of the above plus the date and time of entry and of exit of patients into each unit of $\mathrm{UH}$, origin and destination unit.

3. Hospital bed capacity: number of available beds in each unit during the research period 
4. Nursing workloads: patient registry number, age, sex, diagnosis, discharge category (discharge, death, transfer), time and daily NEMS measurements at MSICU

5. Costs: Estimated daily bed costs at each unit

We estimated length-of-stay (LOS) distributions for each unit, patient outcome distributions and patient transfer matrix to represent transitions between hospital units. Note that LOS is ward-specific but does not depend on patient type. For all cases, several distributions were considered (Banks [5]) and chosen on basis of Akaike information criterion(AIC, Akaike [1]) and Bayesian information criterion (BIC, Schwarz [42], Hastie et al. [19]), as is common in this line of research (e.g. Shukla et al. [45], Rau et al. [38]).

\subsection{Transition Probabilities}

There were 17,380 patients representing 42,012 internal movements (an average of 2.41 records/patient) represented in the patient flow matrix (Figure A.11). Each transfer has an unique destination. However, if the intended unit is full, then the practice is to transfer the patient to an alternate unit, causing off-service care. In this way, individual off-service decisions are determined probabilistically. Deaths from the MSICU were modeled separately using a logarithmic function (Figure A.13).

During the patient's stay at MSICU, patients receive a NEMS upon arrival to MSICU, and a revised score every morning during their stay in MSICU. Once the patient reaches a NEMS consistent with a L2 type, she attempts to exit the MSICU and reach the new L2 unit. In the baseline scenario, patients exit MSICU if they reach a ward type NEMS. 
174

175

176

177

178

181

182

183

\subsection{Cost Data}

LHSC supplied cost per patient-day for each level of care (Table 1) as well as capital expenditure estimates for 8 and 15 L2 beds (originated for a previous investment in another site). We calculated annualized capital expenditures for the entire range from two to 28 L2 beds by linear extrapolation and 10 year linear depreciation, consistent with Canadian accounting practice (Table A.10).

\subsection{Simulation scenarios and runs}

We evaluated the following scenarios:

1. Capacity increase with a L2 unit: Adding a range from 2 to 20 L2 beds into the existing baseline model.

2. Capacity re-allocation: Maintain a total of 25 beds while shifting capacity from MSICU into the new L2 unit.

3. Capacity re-allocation: Increase the total to 30 beds while shifting capacity from MSICU into the new L2 unit.

Each configuration of each scenario was simulated 200 times, using a one year warm-up period followed by a one year data collection period. A different random seed number was used for each run. Trial run times varied from 20 to 40 minutes using an Intel@ Core i5-2400 CPU 3.10GHz 8GB RAM server.

\section{Results}

\subsection{Model Validation}

Our simulation model captures the individual physician's and nurse's decisions to transfer or discharge individual patients via a macro approach, using LOS distributions for each ward and a probabilistic transition matrix for each patient movement. To validate this approach, we compared patient arrival, throughput, LOS and cost results from the baseline simulation with aggregate 
199 empirical data and cost data from publicly available documents such as LHSC's

financial statements LHSC [28] and the Canadian Institute for Health Information yearly reportsCIHI [10]. The model is accurate in reproducing entry data, MSICU LOS and cost data (Table 2). Average throughput is within 1\% of empirical data, while total LOS is within $0.4 \%$. MSICU LOS is slightly high $(2.9 \%)$ but with a lower standard deviation, resulting in no statistically significant difference compared to the empirical data. We concluded that the simulation model is sufficiently valid to address the research questions. Results for all scenarios are summarized in Table 4.

\subsection{Scenario 1: Capacity increase with a New L2 unit}

We evaluated the addition of extra beds in a general-purpose "net new capacity" step-down ward. We simulated a range of 2 to $20 \mathrm{~L} 2$ beds in a dedicated unit immediately downstream from the MSICU and did not alter the capacity of the MSICU ( 25 beds). We first assessed the impact of the new capacity on off-service utilization. In the base case (i.e. no new capacity), the existing specialized Level 2 units (MOTP, CCU, NOBS) have a combined off-service load of 573 patients/year. This value drops to 225 patients/year as we add L2 beds. In the base case, the Level 3 units (MSICU and CSRU) have a combined off-service of 621 patients/year. As L2 beds are added, the off-service reduces to approximately 110 patients/year, representing a reduction of $82 \%$. This reduction may represent a significant improvement in terms of patient care, as approximately 500 more Level 3 patients are now able to be transferred to their intended wards.

Next we evaluated the impact of the new L2 beds on throughput. The addition of an L2 unit increases MSICU throughput up until 8-10 new beds where it stabilizes at approximately 1,068 patients/year (Figure 2). The L2 unit's throughput grows until 12-14 beds are added, reaching 730-732 patients/year. 


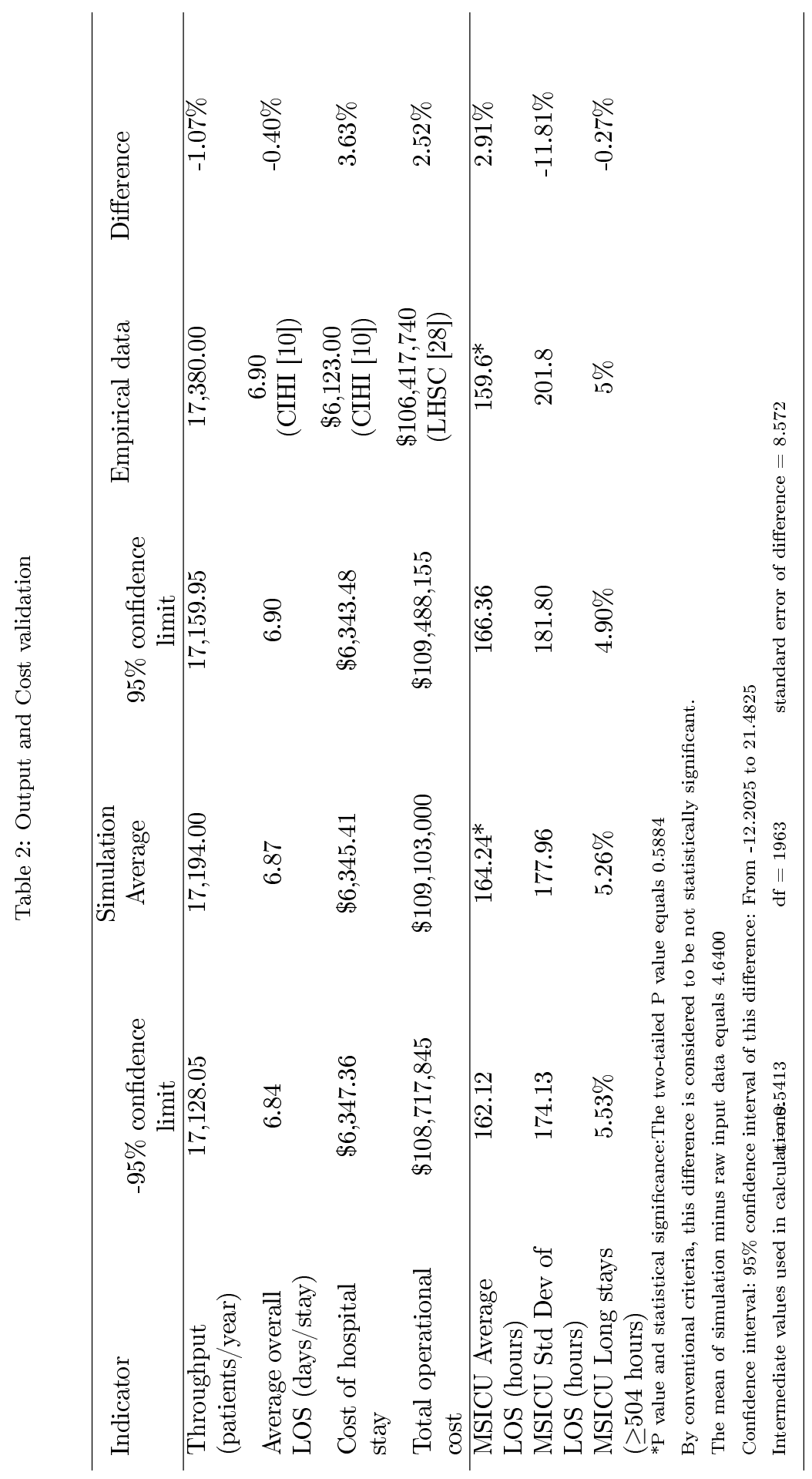




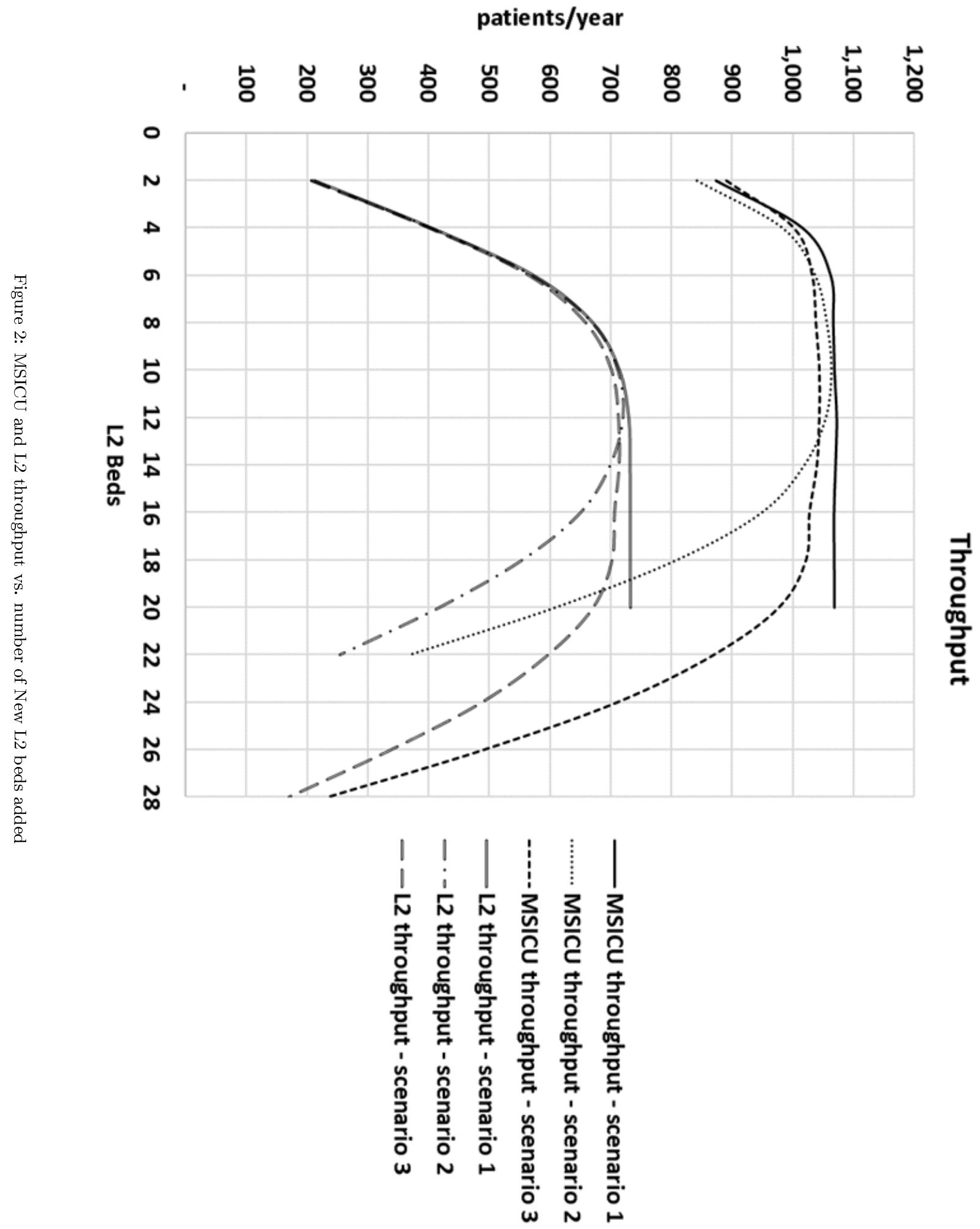


226 This suggests that until the L2 unit capacity reaches 12 beds, MSICU is still

237

238 hosting "step-down ready" patients but after that point there is little clinical need for extra beds.

Utilization and LOS have a similar pattern (Figure 3). The MSICU has a high initial utilization rate (above 85\%) that drops dramatically as L2 capacity is increased, eventually stabilizing around $29 \%$ at 12 beds. As L2 beds are added, there is a rapid decline in MSICU LOS until we reach 12 beds, where it stabilizes at approximately 59 hours (Figure 4). Moreover, the percentage of patients who stay more than 21 days in the MSICU reduces to approximately zero after 8 beds. This suggests that additional L2 capacity allows the MSICU to return to its clinical role of intensive care.

Finally, we find that a maximum of 29 total beds (MSICU and L2 beds combined) are ever occupied, which exceeds MSICU's current capacity of 25 beds. This supports further investigation of increased capacity in MSICU in Scenario 3 (Section 4.4).

\subsection{Scenario 2: Capacity re-allocation}

This scenario involves creating a new L2 unit, but rather than creating new capacity, beds in the existing MSICU would be closed and reallocated to the L2 unit. This scenario would apply in case the hospital does not have additional space to create a new L2 unit or budget for net new beds. Off-service loads are slightly higher than in Scenario 1. The minimum off-service load is reached when there are 15 MSICU and 10 L2 beds, leading to total L3 off-service load of 150 instances per year. This figure represents an improvement in terms of patient care, as approximately 470 patients can now be transferred to their intended wards. Off-service performance then deteriorates as more beds are shifted from MSICU to the L2 unit. MSICU becomes a bottleneck and upstream units are forced to send off-service patients to CSRU. This situation represents 


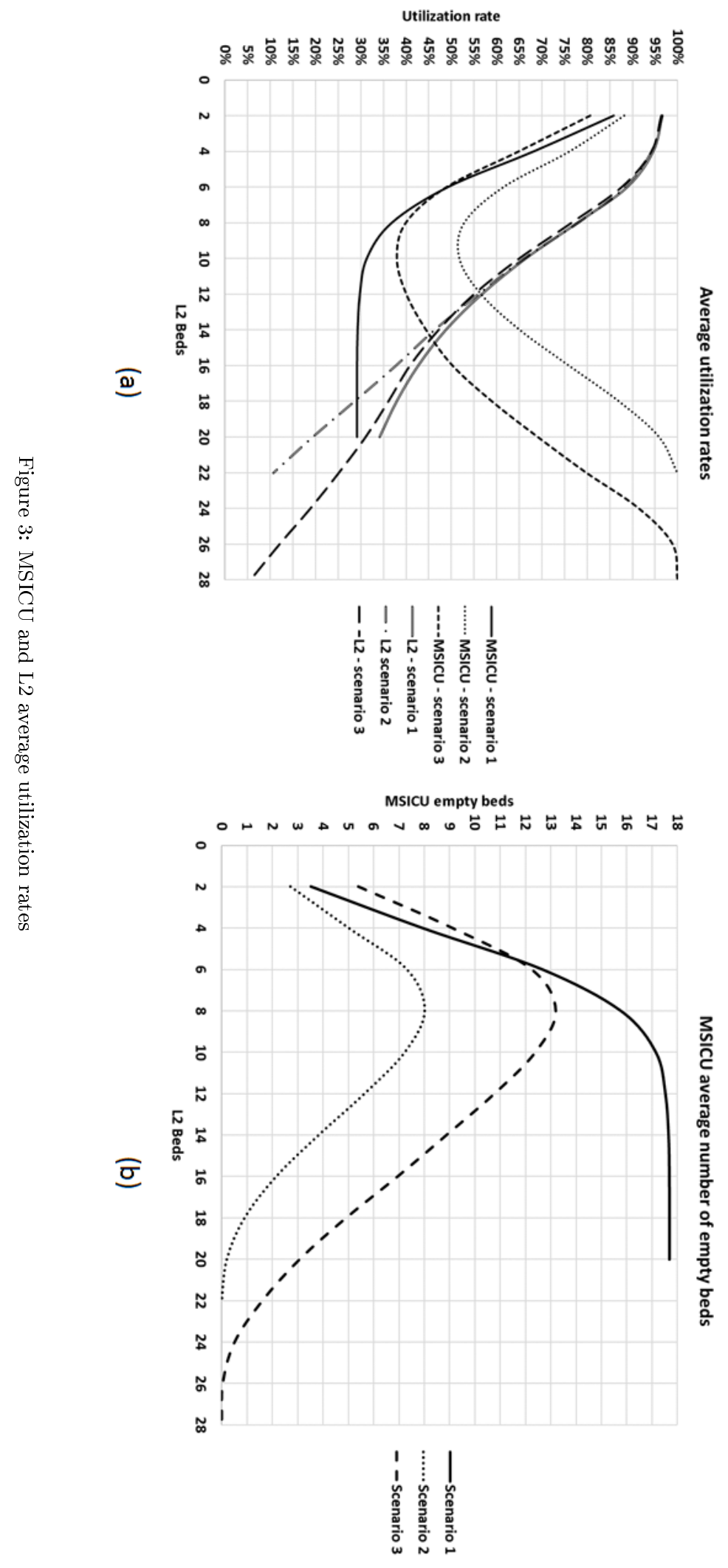



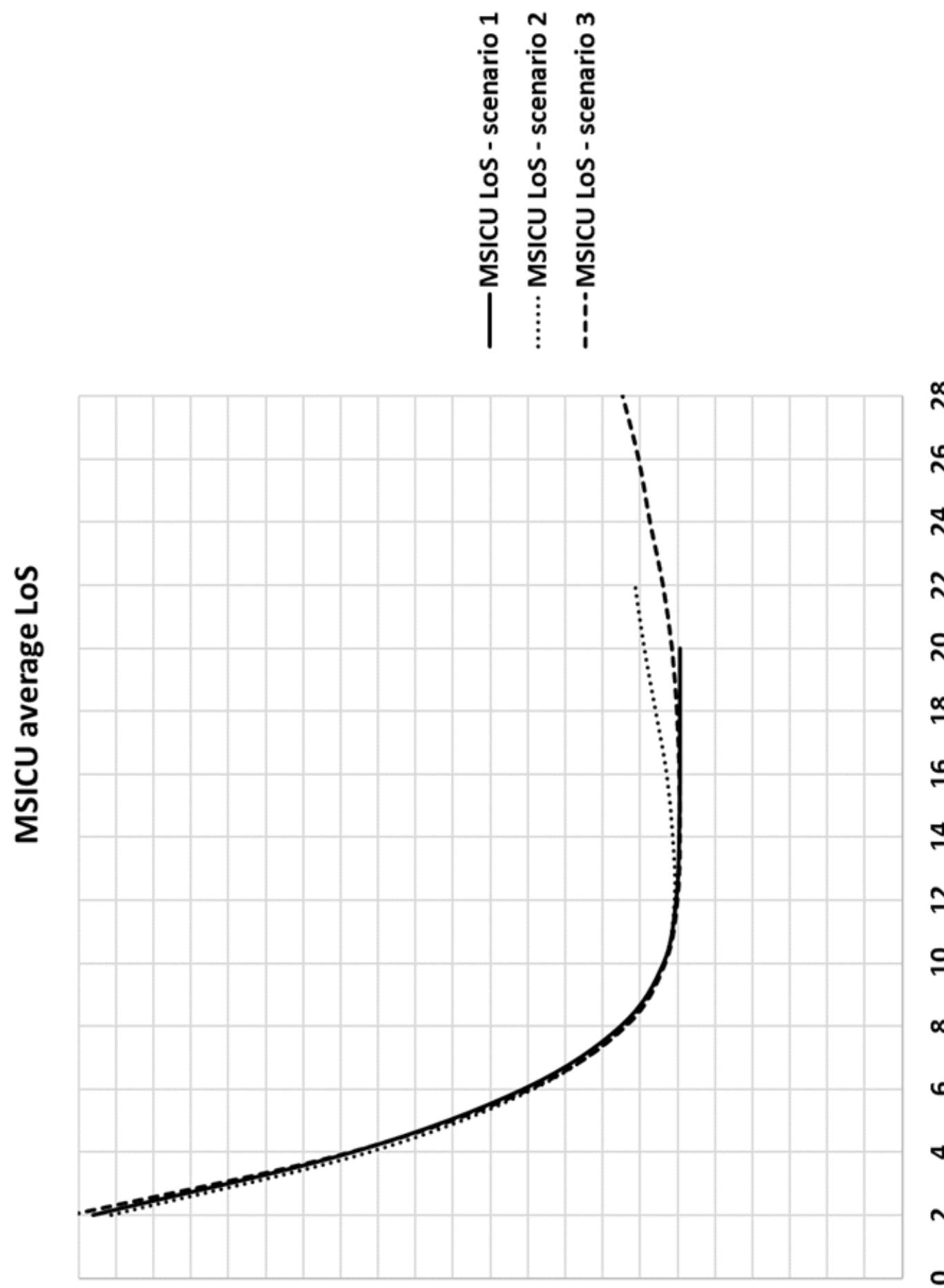

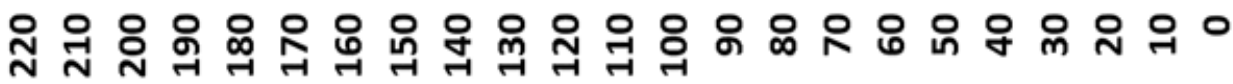
quว!̣ed/sınoH 
253 a clear clinical misfit, as CSRU is a cardiac surgery unit, where both nurses and ${ }_{254}$ physicians are heavily specialized in cardiac care. The treatment of patients ${ }_{255}$ intended for MSICU in CSRU could result in deterioration of patient care and 256 disruption of the cardiac surgery patient flow.

257 MSICU throughput improvements start when there are 4 beds reaching an 258 optimal value of 1,050 patients/year when there are 15 MSICU and 10 L2 beds 259 (Figure 2). The L2 unit reaches a peak throughput of 720 patient/year when 260 there are $13 \mathrm{MSICU}$ and $12 \mathrm{~L} 2$ beds. This is similar to the maximum throughput ${ }_{261}$ achieved when we evaluated net new capacity in Scenario 1. After that point, ${ }_{262}$ as MSICU beds are converted into L2 beds, the smaller number of MSICU beds ${ }_{263}$ becomes a bottleneck to upstream units such as the ED and OR. Patient flow 264 reduces significantly and blockage becomes more frequent in those units due to 265 high utilization rates at MSICU. As the L2 unit is a dedicated downstream unit 266 of MSICU, its throughput is also reduced after $12 \mathrm{~L} 2$ beds.

267 MSICU LOS begins to improve after creating 4 L2 beds. The minimum LOS 268 of $60.66 \mathrm{~h} /$ patient occurs when there are $13 \mathrm{MSICU}$ and $12 \mathrm{~L} 2 \mathrm{beds}$, representing ${ }_{269}$ a $63 \%$ improvement relative to the base case. As more capacity is shifted to L2 ${ }_{270}$ beds, the LOS rises back to the $70 \mathrm{~h} /$ patient mark. This reduction represents a 271 gain of at least 2,000 patient-days/year in the combined MSICU and L2 capacity. ${ }_{272}$ This confirms our earlier finding in Scenario 1: a L2 unit provides opportunity 273 for MSICU to go back to its clinical role, with minimum overstay.

${ }_{274}$ This result makes sense due to the drastic reduction in long-stay patients in ${ }_{275}$ the MSICU (MSICU LOS above 21 days - Figure 5). Those patients often reach ${ }_{276}$ a L2 NEMS, triggering their stepping-down into the New L2 unit. The result is 277 higher availability of MSICU beds (Figure 3 (b)) for patients originating from 278 upstream units, thus improving patient flow. 

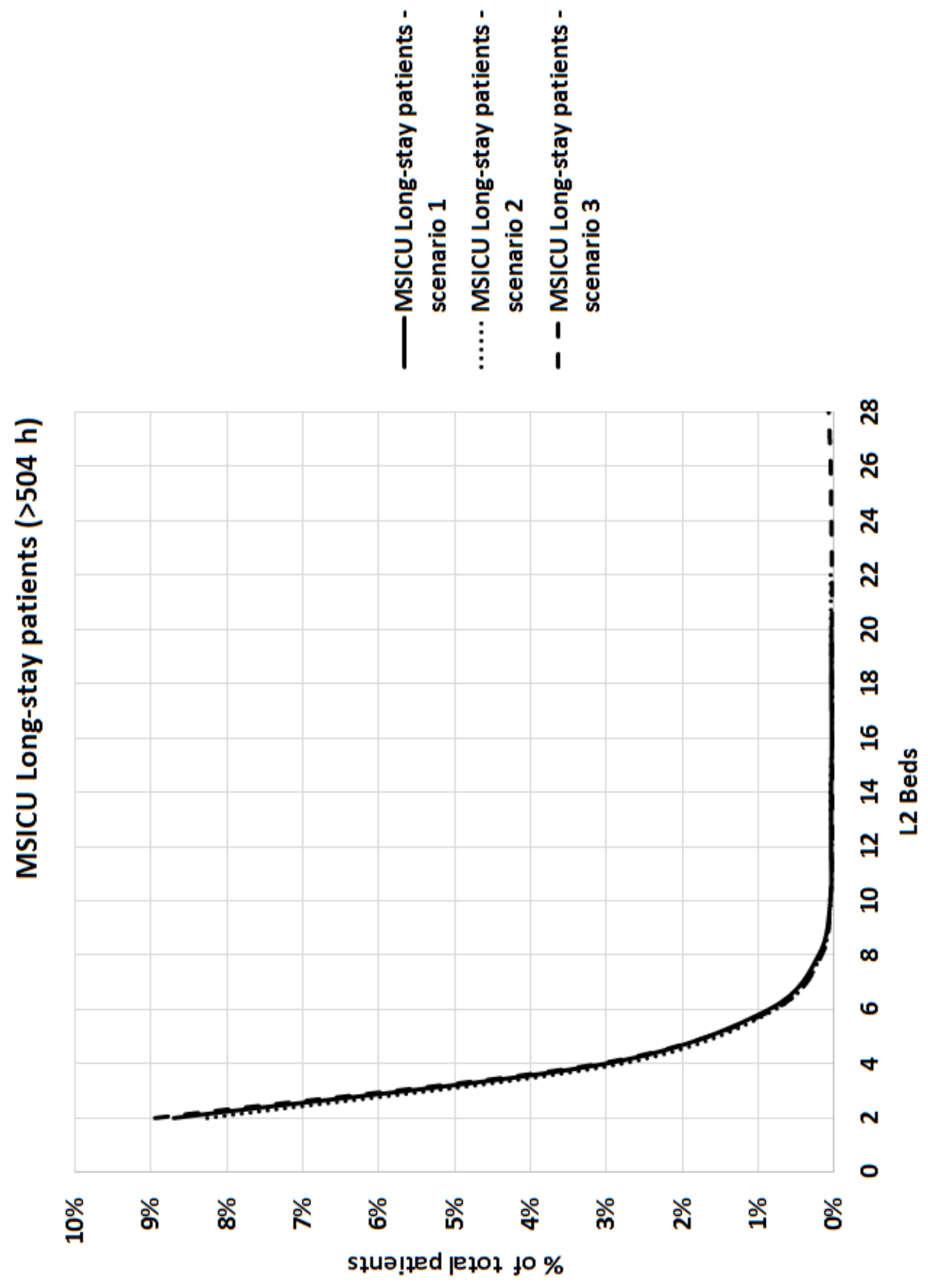
279 4.4. Scenario 3: New capacity and capacity reallocation

280 In this scenario we evaluated reallocation of beds along with net new capacity

${ }_{281}$ of 5 beds. Off-service loads are between the two previous scenarios, with lowest

282 values within a range of 20 to 16 MSICU beds. MSICU throughput is stable

283 at 1,050 patients/year anywhere from 20 to 16 beds reaching a peak of 1.063

${ }_{284}$ patients/year (Figure 2), while L2 throughput is stable within the range of 10

285 to 18 beds, peaking at 720 patients/year. Therefore any mix from $20 \mathrm{MSICU}$

286 and $10 \mathrm{~L} 2$ beds to $12 \mathrm{MSICU}$ and $18 \mathrm{~L} 2$ beds have comparable results with the

287 Scenario 2 while providing a stable combined throughput. MSICU utilization

288 rates are also significantly lower than in the in Scenario 2, as seen in Figure 3.

289 With MSICU reaching a minimum slightly below 40\% (20 MSICU and 10 L2)

290 and reaching a balanced utilization of approximately $45-47 \%$ at $16 \mathrm{MSICU}$ and

2914 L2 beds.

292 Any mix from $20 \mathrm{MSICU}$ and $10 \mathrm{~L} 2$ beds to $12 \mathrm{MSICU}$ and $18 \mathrm{~L} 2$ beds

${ }_{293}$ yield approximately 60h LOS, similar of the previous scenarios (Figure 4). As

${ }_{294}$ in previous analysis, the ability to step down long stay patients with low NEMS

295 plays an important role in improving patient flow (Figure 5).

296 4.5. Costs

297 In all three scenarios a significant cost saving was possible relative to the 298 current cost of $\$ 3,500 /$ patient-day in MSICU (Figure 6). Combined MSICU

299 and L2 costs decrease steadily in all scenarios until they reach a minimum of зоо $\$ 2,869.46 /$ patient-day at 12 L2 beds under scenario 3 . From that point on, under sо1 all scenarios, costs escalate, but never reach the current baseline cost. This result 302 can be explained by two factors. First, L2 operational costs represent only $57 \%$ зоз of MSICU's. Initial increases in L2 capacity permit a timely step-down and ${ }_{304}$ immediate savings occur. Second, after 12 L2 beds, the new L2 unit starts to ${ }_{305}$ have idle capacity. This is due to lack of demand in Scenario 1 and to MSICU 
constrained flow in Scenarios 2 and 3. Idle L2 beds carry high fixed costs in the form capital expenditure, thus forming the upward half of the curve.

\subsection{Increased arrivals}

By increasing throughput capacity, the hospital may receive more patients. Thus, we simulated an increase in the inpatient flow from ED and OR to see how well our optimal configurations stand a hypothetical surge in demand. For Scenario 1, we focused on ED and OR, where inpatients spend relatively little time waiting for their disposition from ED, or their scheduled surgeries in $\mathrm{OR}^{1}$. A $10 \%$ increase in ED and OR demand, representing an extra 1,200 patients/year, is enough to negate any gains achieved by the introduction of net new L2 capacity (Table 3).

Next, we focused on MSICU performance in Scenario 3. The inpatient surge is mostly absorbed by MSICU and L2, reaching maximums of 1,300 and 930 patients/year respectively (Figure 7 (a)). There is a gradual shift in the optimum bed mix to $16 \mathrm{MSICU}$ and 14 L2 beds. Utilization rates increase accordingly, reaching approximately $60 \%$ in the optimum throughput bed mix (Figure 7 (b)). MSICU LOS changes little with the increase in ED and OR demand (Figure $8(\mathrm{a}))$. At $30 \%$ increase in demand, MSICU LOS rises to approximately 65 hours/patient. In terms of LOS, the optimal configuration shifts slightly to 16 MSICU beds and 14 L2 beds. Thus, the increase in inpatient volume does affect the values of MSICU patient flow indicators but the optimal solution is robust to increased volumes.

Higher utilization in MSICU triggers congestion upstream. Particularly in the ED, at the $30 \%$ demand increase, there is an increase of $317 \%$ in the use of

\footnotetext{
${ }^{1}$ This is not the wait time to enter the ED, as we simulated only inpatient flow. This wait is for patient disposition, i.e. the moment the patient is ready to receive a decision to admit
} until the true admission and transfer to the intended location. 


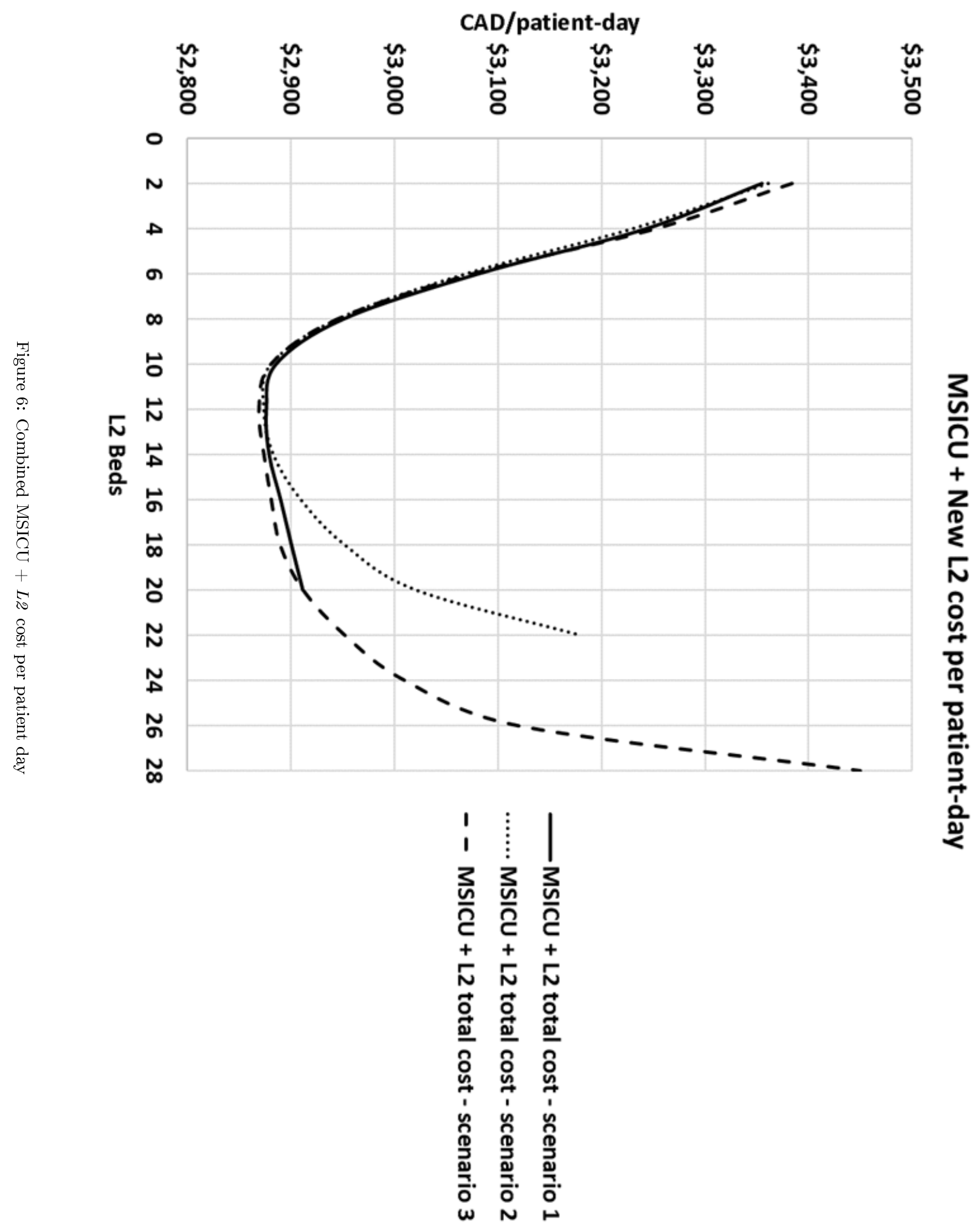




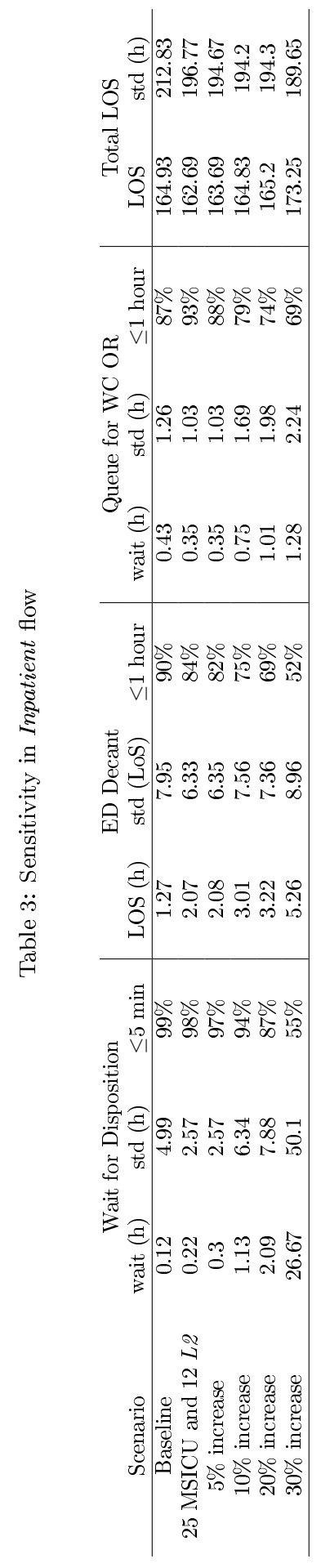




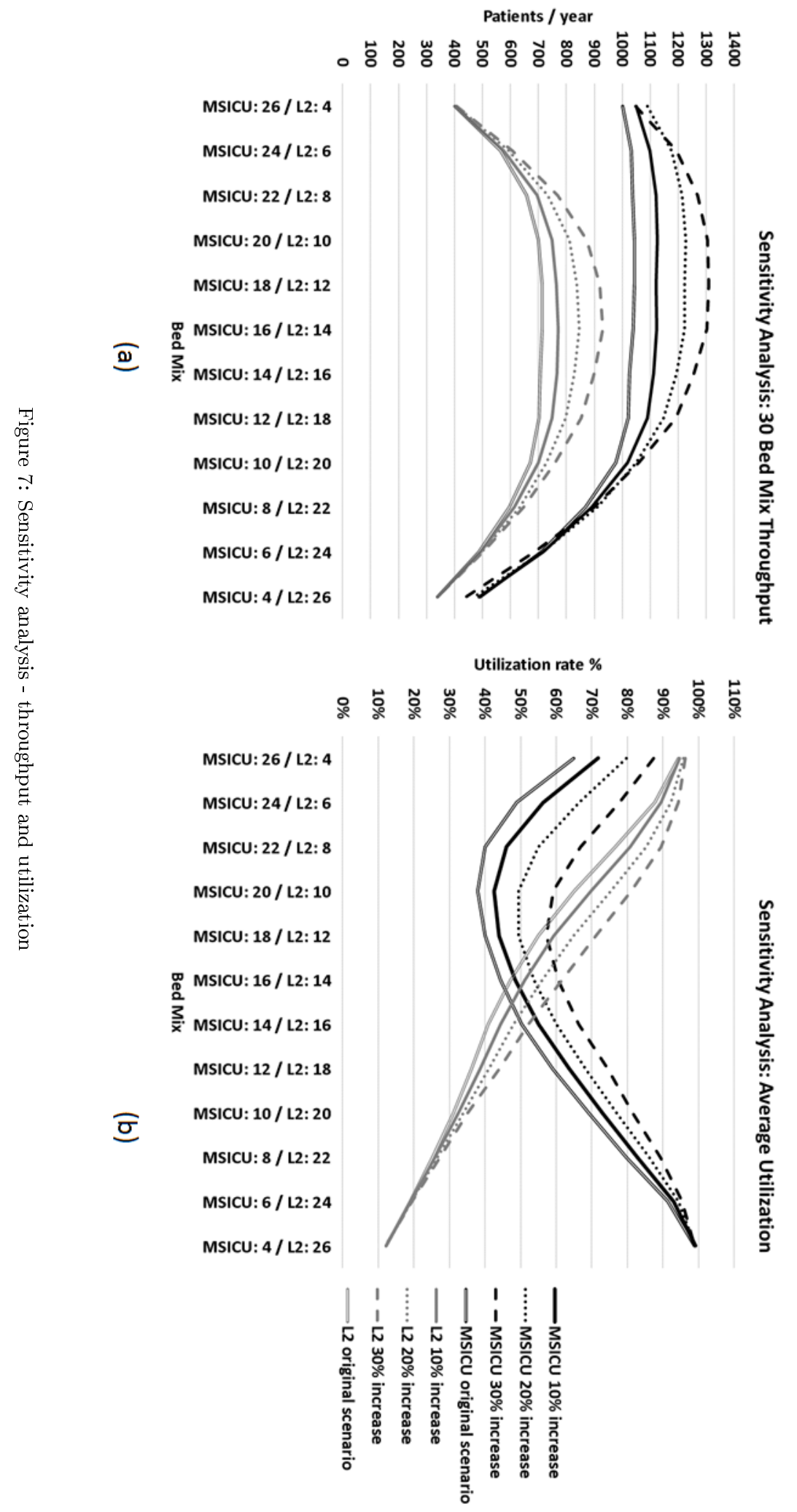



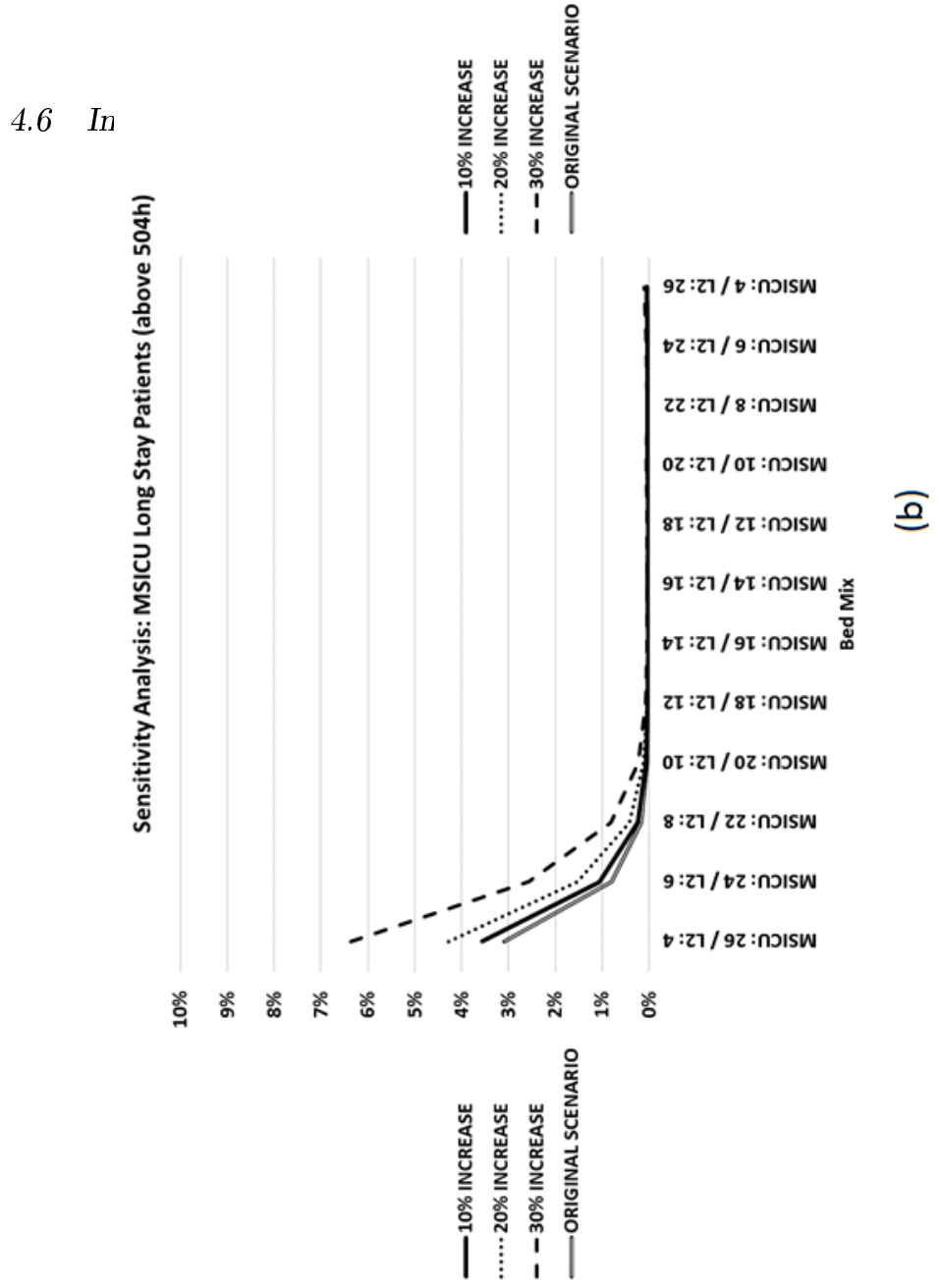

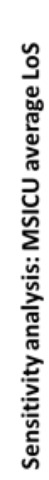

$9 z: z 1 / \bullet:$ ก)

$๑ z: z า / 9:$ กวเsw

$22: 27 / 8$ :กวิsw

$0 z: 27$ / or : กวเม

$8 \tau: 27 / 2 \tau:$ ก)

$9 \tau: \tau 1 / t \tau:$ กวเSW

ธี ז ז

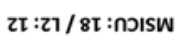

or :z / 02 : กગısw

$8: 27 / 2 z: n כ 15 W$

$9: 21 /$ ๖z:กวเsw

๑: : / 92 : กวเsw

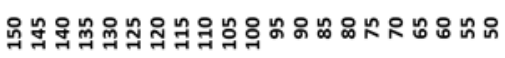

sinoy u! S07 
temporary ED beds (the ED decant ward, with a capacity of 6 beds).

Combined MSICU and L2 patient-day costs remain similar even with a $30 \%$ inpatient arrival increase (Figure 9 (a)), but the minimum shifts slightly from 18 MSICU beds and 12 L2 beds to 16 MSICU beds and 14 L2 beds. Figure 9 (b) shows that Scenario 3 had a robust range in terms of total cost, with an approximate value of $\$ 14.5$ million/year for a range of 18 to 12 MSICU beds and 12 to $18 \mathrm{~L} 2$ beds. In the $30 \%$ demand increase, however, total cost is continuously decreasing, with the optimal mix costing an extra $\$ 4.7$ million/year, or $33.4 \%$ more than Scenario 3. This a direct result of MSICU's diminishing capacity to absorb the increased demand. However, even a 30\% increase in ED and OR volume in the optimal configuration is not enough to return total MSICU and L2 cost to the level of the baseline scenario of $\$ 24$ million, demonstrating the impact the L2 unit has in UH's cost structure (Figure 9 (b)).

\subsection{Management Feedback}

Preliminary results from this analysis were presented to a team of managers of LHSC in January 2017. The team consisted of the Vice President of Access and Flow, the Director of Clinical Redesign, the Director of Critical Care, and the City-wide Chair and Chief of Medicine, among others. Our research confirmed their intuition about the need for an L2 unit, but revealed unanticipated findings in terms of the L2 unit's ability to improve flow, reduce MSICU LOS (63\% from current levels) and reduce cost by approximately $40 \%$. Implementation of the new L2 unit is likely to occur in the near future.

The managers in attendance stated that our model was the first large scale DES model to be used in UH. Our results led to questions about the need for a clinical study about the MSICU long-stay population and their desired care pathway, as well as about UH's capacity to deal with increased demand. They concluded that our DES model provides support for further L2 capacity studies 

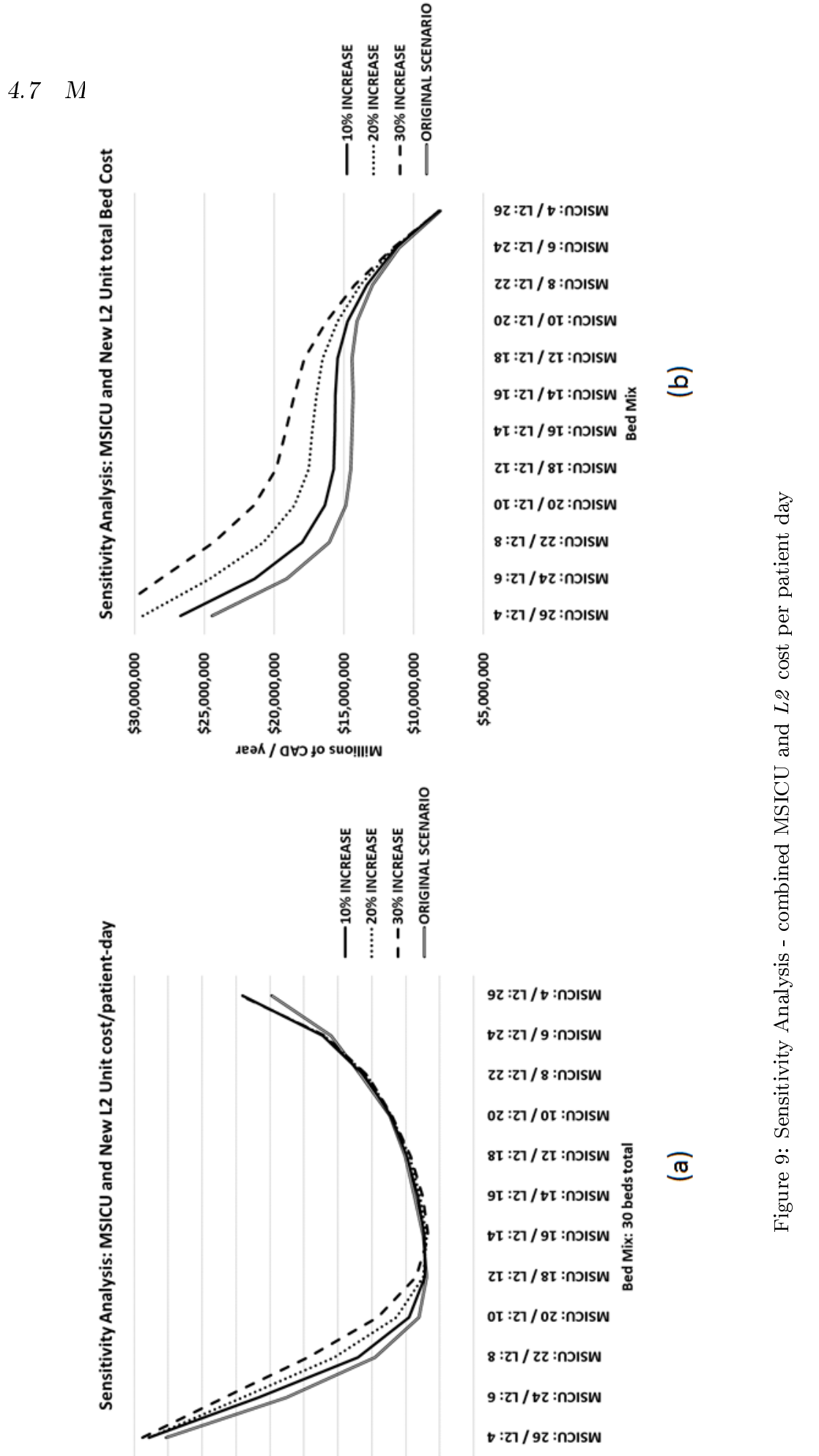

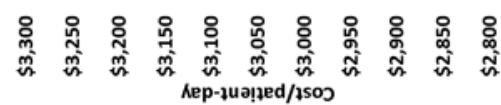


${ }_{357}$ in other LHSC sites as well, such as Victoria Hospital's L2 clinical redesign.

\section{5. Conclusions}

359 We found that there are considerable performance gains to be made with the 360 addition of a step-down unit. In all scenarios, the optimal performance occurs

361 when there are approximately 12 L2 beds yielding MSICU LOS of approximately

36260 hours/patient, a cost reduction of $18 \%$ per patient-day and $40 \%$ in total cost

${ }_{363}$ per year (see Table 4).

364 It has been recognized for some time in health care simulation literature 365 that implementation does not necessarily follow the recommendations proposed 366 by researchers (Lane et al. [27], Bountourelis et al. [7], Brailsford et al. [8]). 367 Forsberg et al. [14] report that from 59 articles surveyed in the literature, only 36814 mentioned implementation. Many reasons for this gap are possible, such as 369 lack of client involvement, lack of clear methodology and failure to communicate results properly. To avoid such problems, we followed a general framework of the methodology based on previous literature (Lane et al. [27], Bountourelis et al. [7], Forsberg et al. [14]) and the best practices (Karnon et al. [21]). In particular, stakeholders were involved right from the beginning of the study, validating and providing input in every step of the research.

Our model has limitations. Our data represents only inpatient arrivals so our model does not consider balking or reneging at any entry points. This means that all ED and OR arrivals are admitted patients and must go through the system. We use a simplified model of the ED and thus our model does not capture ED congestion. However, we believe that this does not have significant impact on our analysis since ED arrivals that eventually visit MSICU are unlikely to be turned down by UH due to their health status. Also, the Death/Stay/Stepdown routine has a minor drawback: once the patient is prevented from leaving 


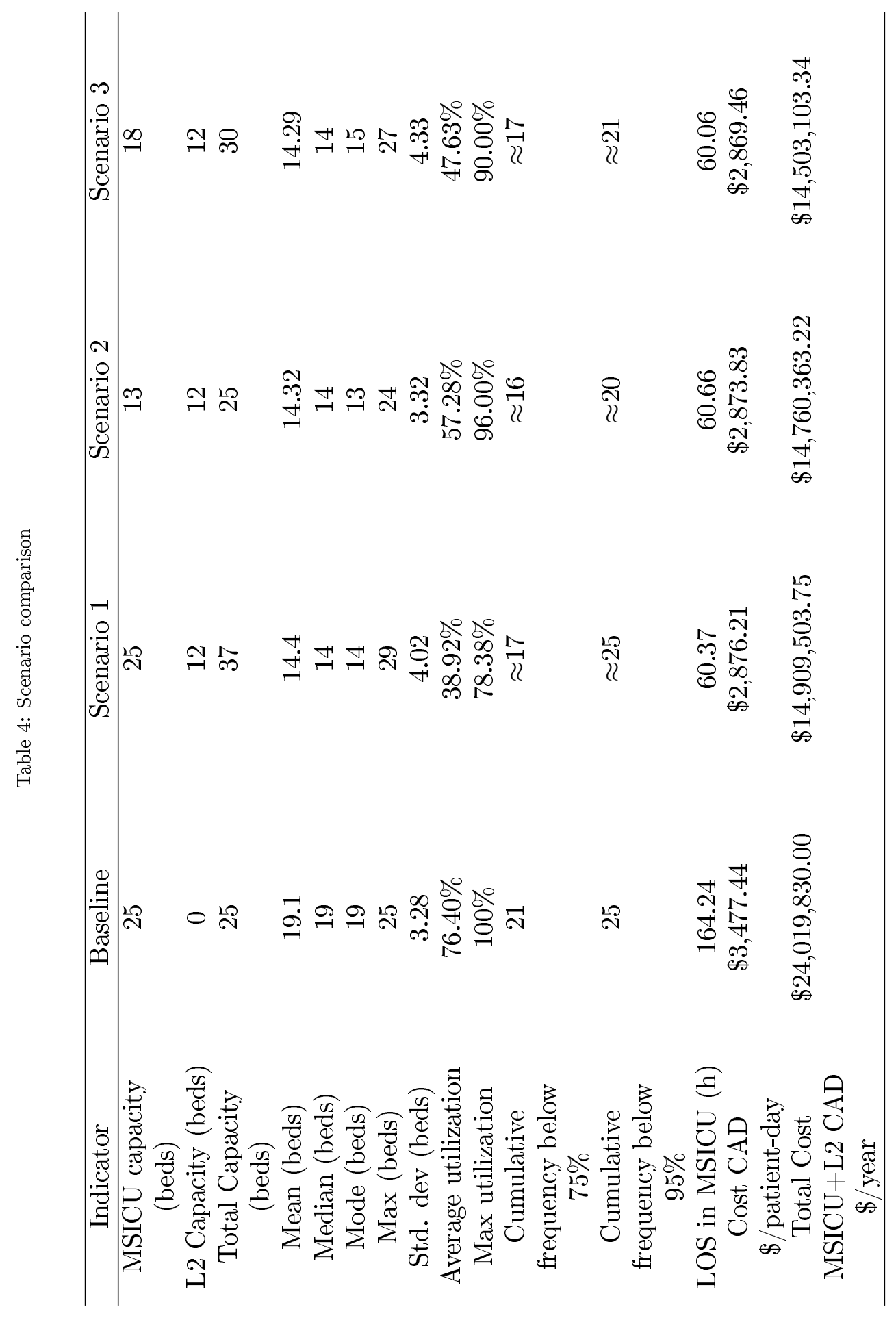


383 MSICU due to blockage downstream, the patient has to wait for the next morn-

384 ing to have a new chance to leave the MSICU. In spite of this drawback, the 385 model validation found accurate MSICU LOS.

386 There are several directions for further research. First, we will explore fur387 ther the pooling effects that one might have from merging inpatient wards 38 and/or other specialized L2 units. These units are all highly congested and 389 susceptible to blockage, bounce-backs and grid-locks. Also, we modeled all 390 routing and discharge decisions between wards and other hospital units proba391 bilistically. An interesting avenue for future research would be to incorporate 392 decision rules for these occurrences. Second, we can use the data set to create 393 predictive models for LOS based on NEMS. These can then be used to create 394 dynamic staffing models. Finally, we will develop an analytical model that in395 corporates MSICU's unique position in which it is squeezed between ED/OR's 396 efforts to minimize wait times and the wards efforts to avoid re-admissions. This 397 may involve a combination of queuing and game theory.

398 Glossary of Terms

39 ADT Admission/Discharge/Transfer temporary entry in pacient management

400 system

401 AIC Akaike information criterion

${ }_{402}$ BIC Bayesian information criterion

${ }_{403}$ CCU Coronary Care Unit

404 CSRU Cardiac-Surgical Intensive Care Unit

405 DES Discrete Event Simulation

${ }_{406}$ ED Emergency Department 
407 ICU Intensive Care Unit

${ }_{408}$ ISPOR-SMDM International Society for Pharmacoeconomics and Outcomes

409 Research - Society for Medical Decision Making modeling good research

410 practices task force

${ }_{411} \quad$ L2 Level 2 unit

412 Level 2 Intermediary level of care, usually used as a step-dwon from an Intensive

$413 \quad$ Care Unit

${ }_{414}$ LHSC London Health Sciences Centre

415 LOS Length of Stay

${ }_{416}$ MOTP Multi-Organ Transplant Unit

${ }_{417}$ MSICU Medical Surgical Intensive Care Unit

${ }_{418}$ NEMS Nine Equivalents of Nursing Manpower Use Score

419 NOBS Neurological Observation Unit

420 OR Operating Room

421 UH University Hospital

${ }_{422}$ AppendixA. Model design details

${ }_{423}$ AppendixA.1. Overview

${ }_{424}$ The Appendix contains a detailed explanations of the DES model (screenshot

425 in Figure A.10) and its input parameters. 


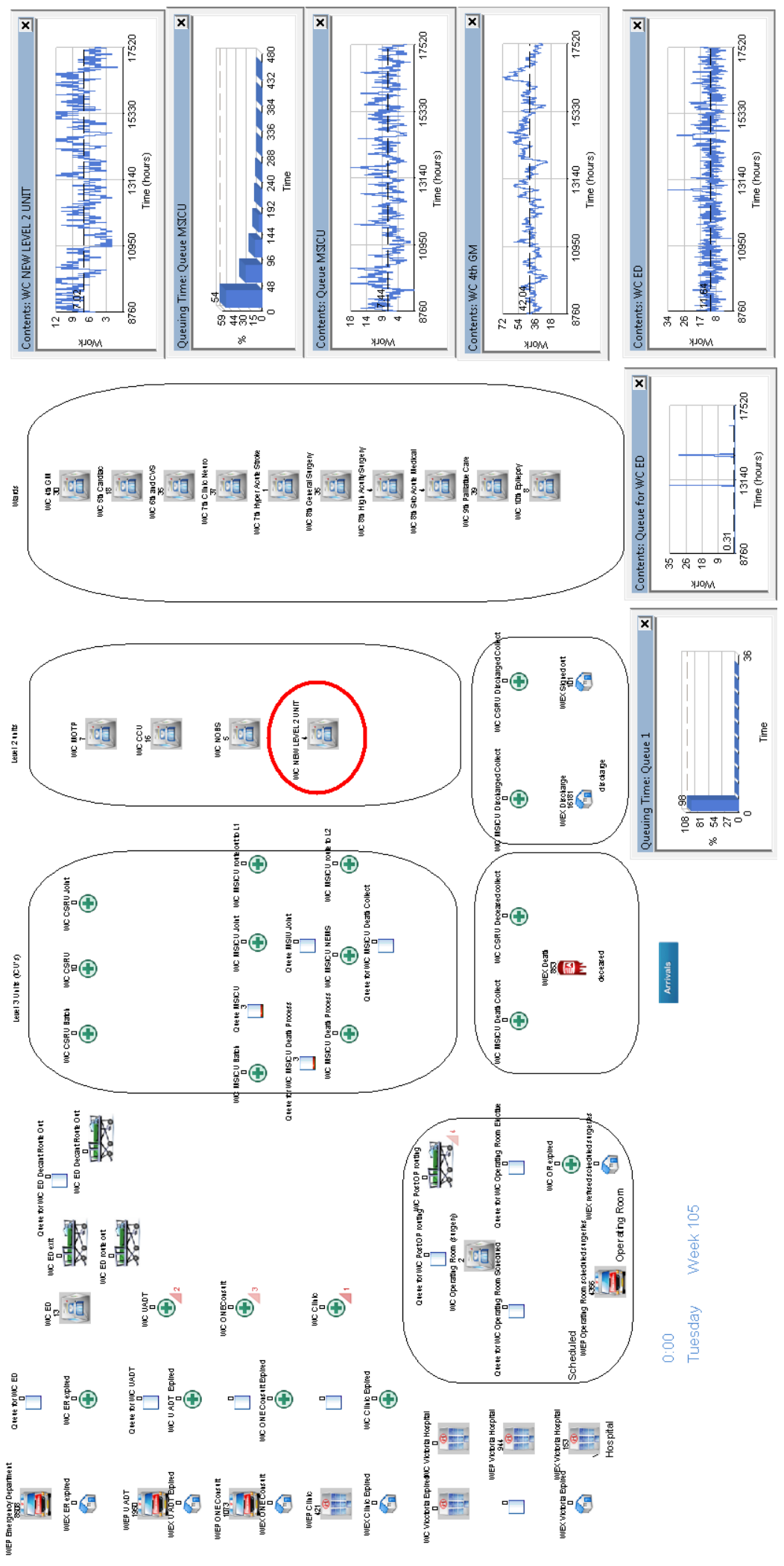

Figure A.10: Screen capture from Simul8 


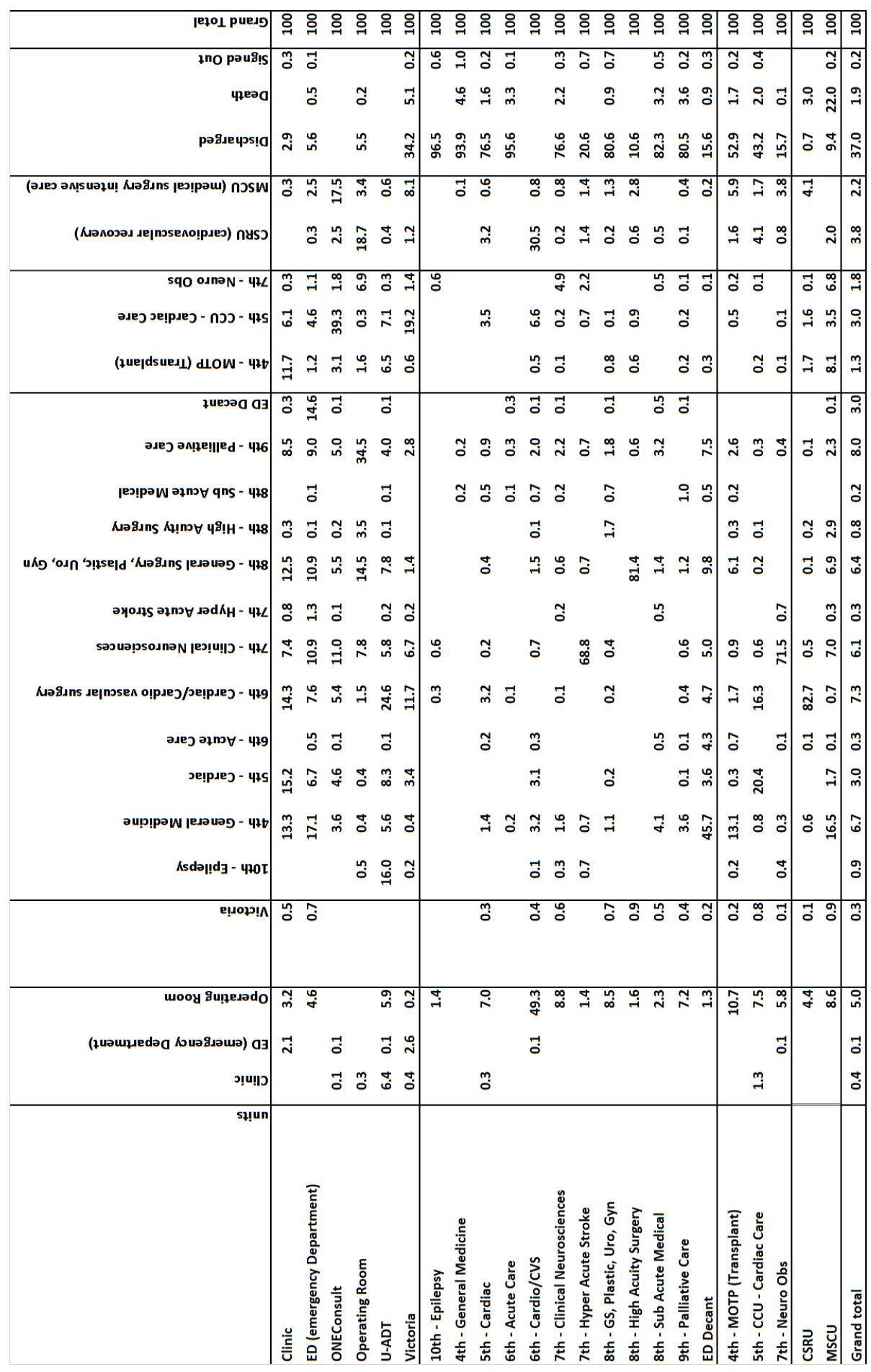

Figure A.11: Inpatient flow matrix (origins in rows, destinations in columns, values in \%) 
Table A.5: Average number of scheduled surgery arrivals per working day

\begin{tabular}{cc}
\hline Hour & Patients / hour \\
\hline 5 a.m. & 2.8 \\
6 a.m. & 6.1 \\
7 a.m. & 1.3 \\
8 a.m. & 1.6 \\
9 a.m. & 2.3 \\
10 a.m. & 1.9 \\
11 a.m. & 0.9 \\
\hline
\end{tabular}

\section{AppendixA.2. ER and OR arrivals}

We modeled seasonality in Emergency Department (ED) and Operating Room (OR) arrivals. The OR performs both scheduled and emergency/unscheduled surgeries. These unscheduled surgeries come from patients either in ED or in other wards that require a surgical procedure and are then transferred to the OR. After surgery they are transferred back to other units in the hospital including MSICU. Unscheduled surgeries happen at any time of the day and any day of the week. Because unscheduled surgeries are comprised of patients already inside the hospital, we modeled the unscheduled surgeries as part of the inpatient flow matrix so they are not part of the external inpatient arrival pattern of the OR.

Scheduled surgeries are originated from outside of the hospital and have a separate arrival pattern. They typically are scheduled between 5am and 11am on weekdays. There was no significant difference between the months or days of the week, but there was variation throughout the day (Table A.5). ED arrivals had variation by day of the week and hour of the day. Our simulation of the ED is simplified by not capturing ED waiting room congestion. Instead, the process starts with the "ready for disposition" time, which is the time when the first assessment has been done and the patient is to be admitted into one of the units of the hospital (Figure A.12). 


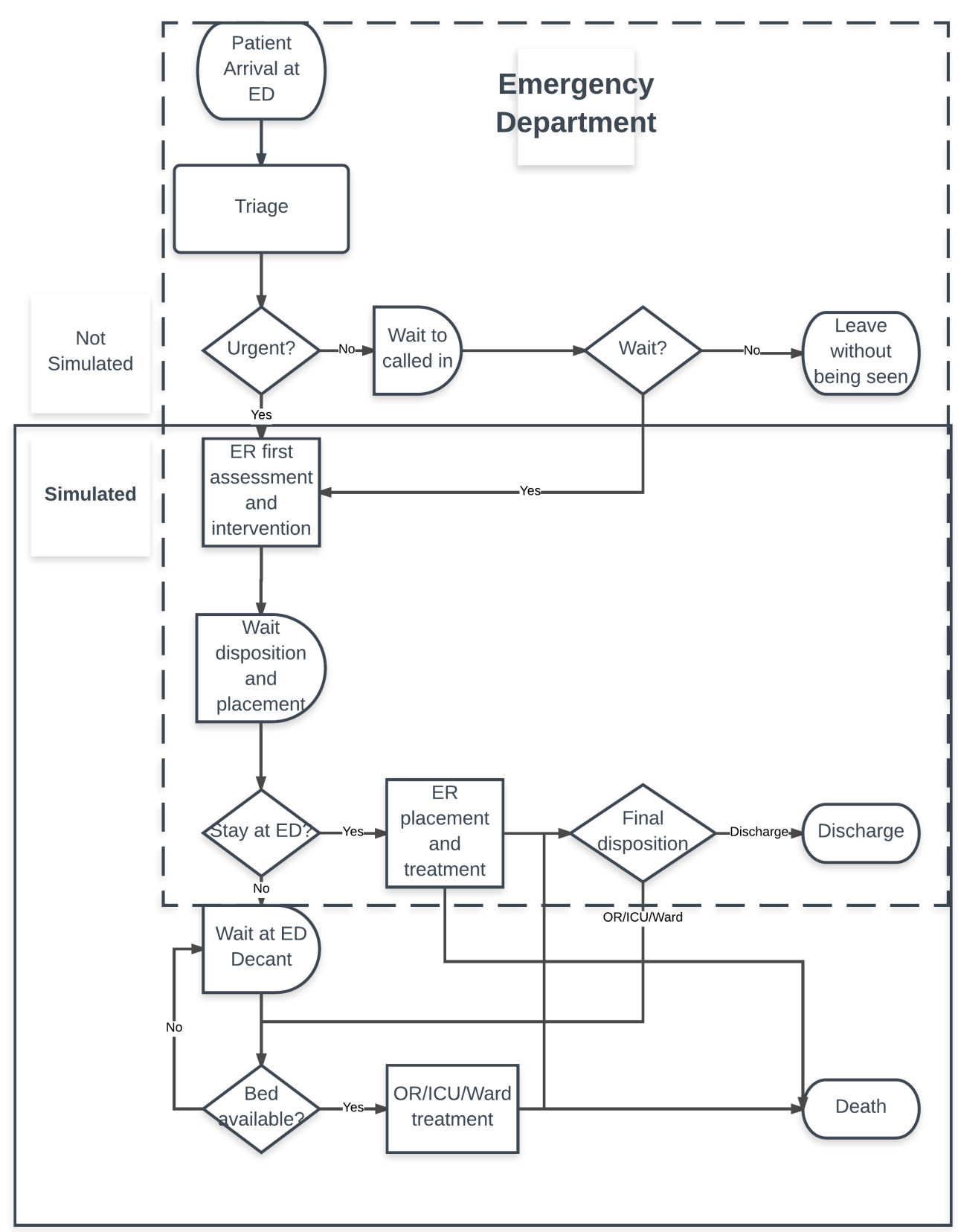

Figure A.12: UH/LHSC ED flow 
446 In our data set there were 8,793 ED inpatients with average daily arrivals 447 ranging from 21 on Sundays to 26 patients on Tuesdays. To avoid the possibility 448 of simulating no patients in a given hour, we divided the day into 4 parts: Late 449 night/Early morning (from 12am to 6am), Morning (6am to 12pm), Afternoon 450 (12pm to $6 \mathrm{pm})$ and Evening (6pm to $12 \mathrm{am})$. ED inpatients are then simulated

\section{AppendixA.3. UH structure and service time parameters}

Ward capacities and service time parameters can be found in Table A.8.

\section{AppendixA.4. Detailed MSICU simulation}

The simulation model of the MSICU starts with a patient arrival from other units (Figure A.14). Upon arrival, the patient receives a "Level 3" NEMS that will represent her current status as a MSICU patient (Table A.9). We then use a fork-join model and divide the patient into "physical" and "procedural" entities. The "physical" entity occupies a bed in the MSICU to ensure that MSICU capacity is not exceeded and that the appropriate queues form when capacity is reached. The "procedural" entity goes to the Death/Stay/Step-down process to model changes in health status and disposition from MSICU.

The first part of the Death/Stay/Step-down process is a daily routine that culminates in either death or survival. From our empirical data we built a logarithmic regression to estimate the probability of death as a function of time in MSICU (Figure A.13). We observed that no deaths occurred after 45 days, so we truncated the function at that point. If the patient dies then the two entities are joined and the patient exits the MSICU and exits the simulation. Thus, MSICU LOS is a consequence of the patient's health progression over time, as opposed to an exogenously generated parameter. If the patient survives, then the "procedural" entity enters a NEMS scoring routine to sample a new NEMS. 


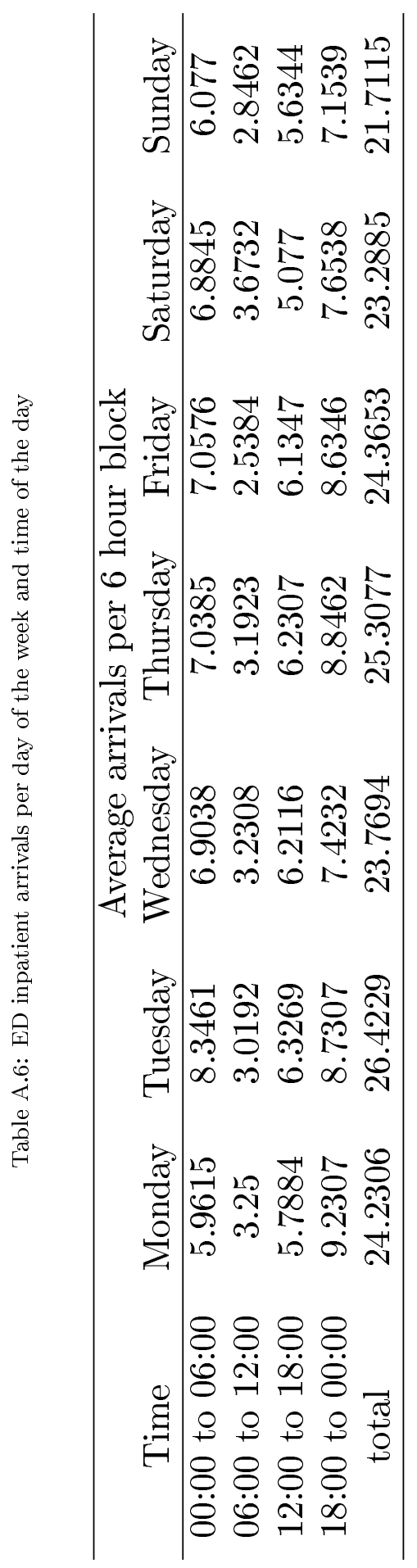




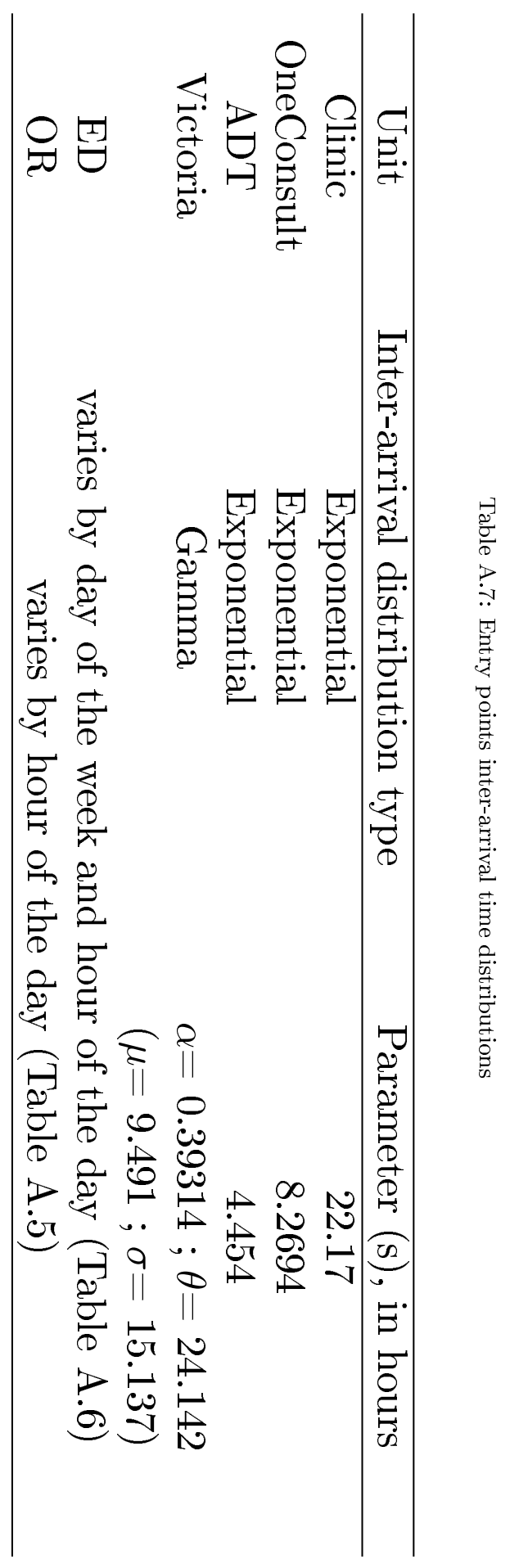


Table A.8: Ward capacities and service time parameters

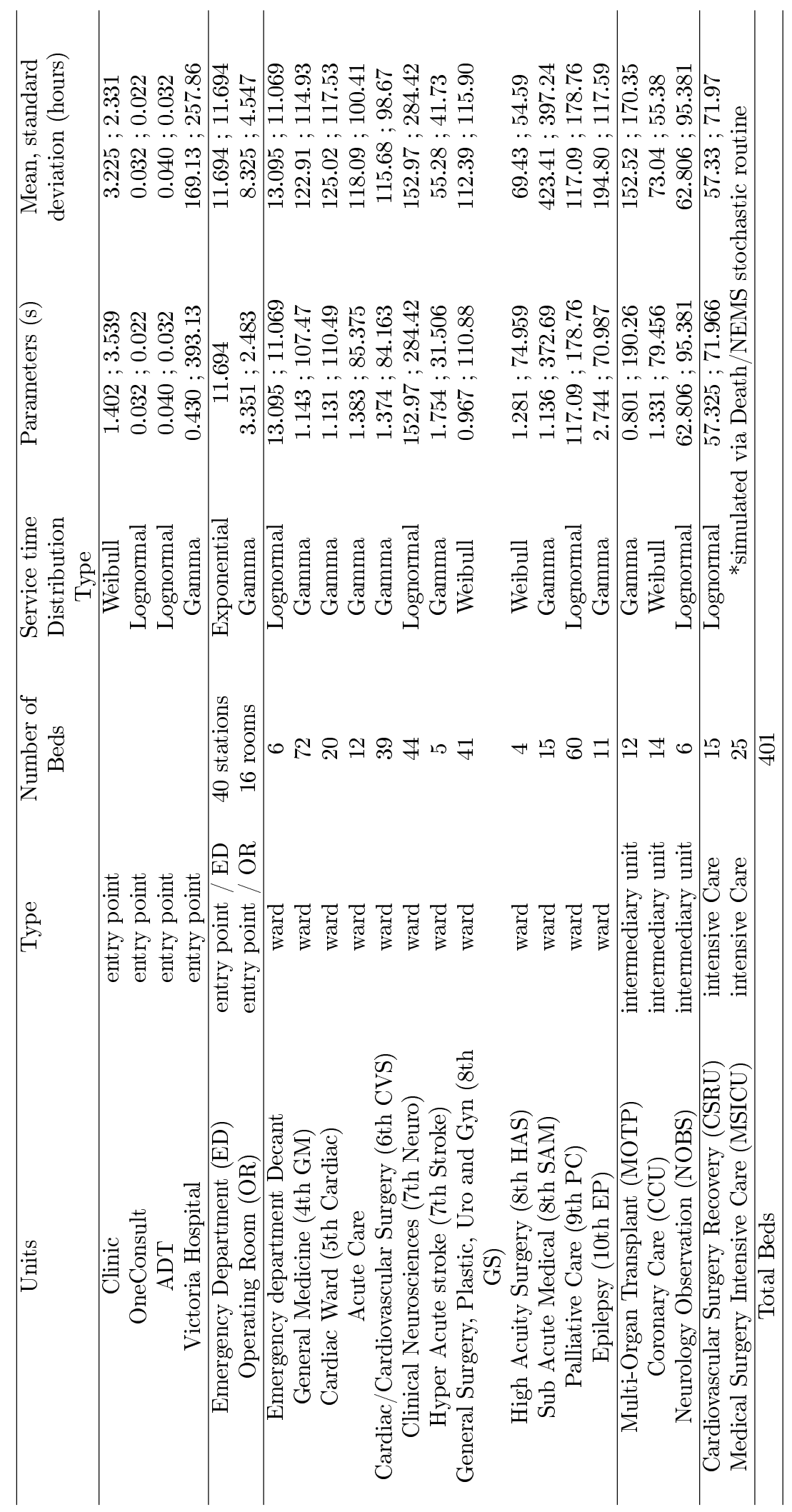




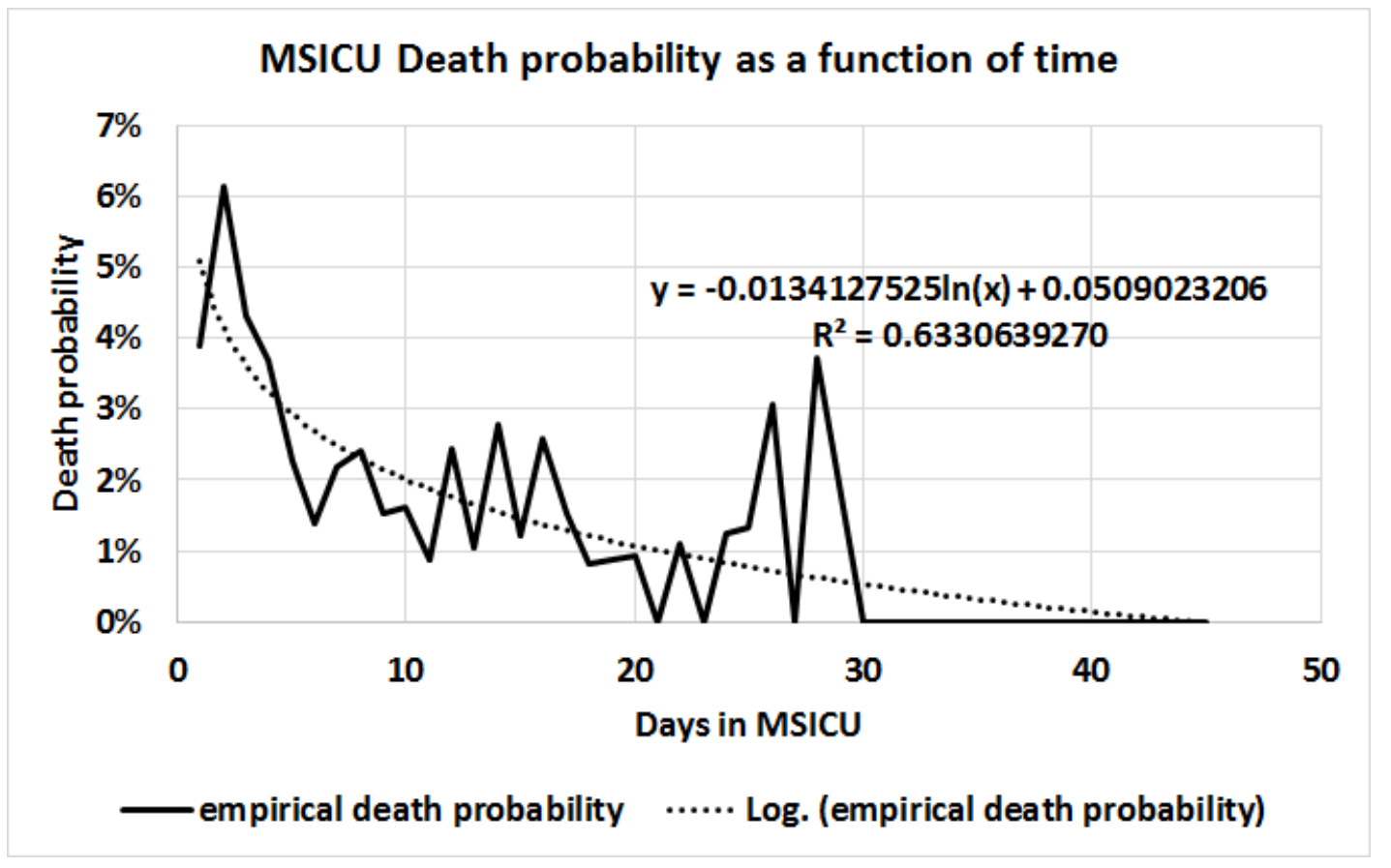

Figure A.13: MSICU Death probability as a function of time 


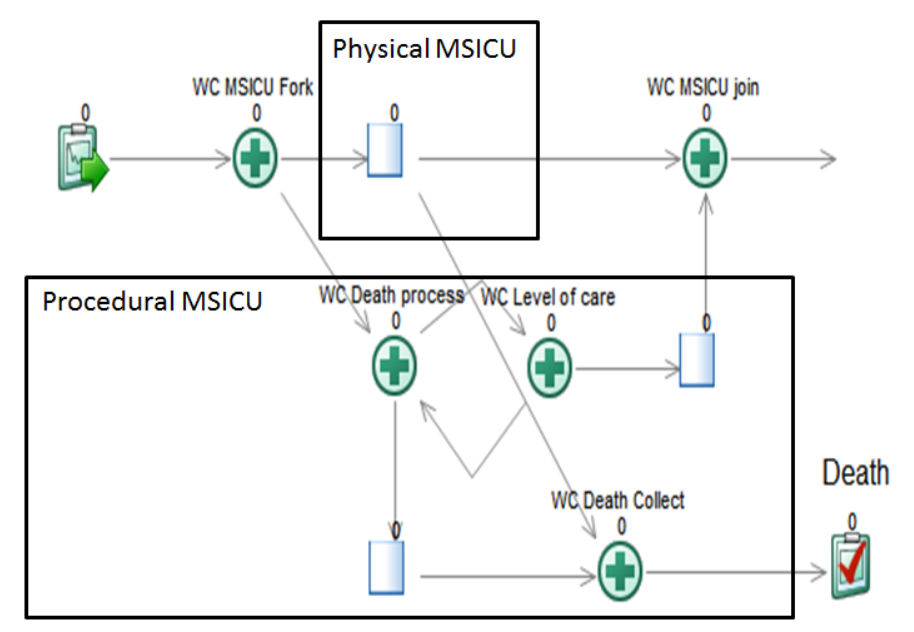

Figure A.14: MSICU Death probability as a function of time. (*WC stands for Work Centre)

472 The score either stays as at "Level 3", or changes to "Level 2" or "Level 1".

473 In case of a "Level 3" NEMS, the procedural entity returns to the death process

474 to repeat the survival and NEMS routine, with updated survival probability

475 based on LOS (Figure A.13). In case of a Level 2 score, in the baseline scenario,

476 the patient still stays at the MSICU since there are no L2 beds available. In the

477 other scenarios, a "Level 2" NEMS will trigger the procedural entity to be joined

478 with its physical entity, exit the MSICU and move to a step-down unit. In the

479 case of a Level 1 NEMS, in both scenarios, the entities join and the patient is

480 transferred to a ward.

481 In case the patient is headed to a unit that is full or blocked, the simula-

482 tion forces the procedural entity to return to the death process and await the

483 next morning for new death odds and NEMS scoring. This procedure guar-

${ }_{484}$ antees that every patient goes through the death/stay/step-down process once

485 every day inside MSICU . The process continues until a patient is able to move

486 downstream. 
Table A.9: NEMS probability

\begin{tabular}{cc} 
& NEMS Probability \\
\cline { 2 - 2 } Level 1 & $7 \%$ \\
Level 2 & $24 \%$ \\
Level 3 & $69 \%$ \\
\hline Total & $100 \%$ \\
\hline
\end{tabular}

487 Note that this captures the fact that a patient's health fluctuates over time 488 and may improve or deteriorate. This model also allows for overstay patients 489 to have their health change due to congestion downstream and captures sud490 den deaths in the MSICU with a more detailed distribution than the one used ${ }_{491}$ elsewhere in the hospital, reflecting the high risk of the patient.

492 AppendixA.5. Capital expenditures estimates

${ }_{493}$ Hospital stay cost data was retrieved from the Canadian Institute for Health 494 Information (CIHI [10]). Operational cost and capital expenditures were ob495 tained via consultation with LHSC Decision Support Staff and publicly available 496 financial statements (LHSC [28]). Capital expenditures were linearly extrapo${ }_{497}$ lated from estimates of 8 and 15 beds ( $\$ 3$ million and $\$ 5$ million respectively) 498 and linearly depreciated over 10 years per Canadian accounting practice (Table 499 A.10).

500

501 502 503 504 505 [1] Akaike, H., 1974. A new look at the statistical model identification. IEEE 506

AppendixA.6. Model validation

In the one year period of the data set, there were in total $\mathrm{N}=17,380$ inpatient arrivals, while our simulation averages 17,350 , well within the $95 \%$ confidence intervals (Table A.11).

\footnotetext{
Transactions on Automatic Control 19 (6), 716-723.
} 
Table A.10: Level 2 unit capital expenditure estimates

\begin{tabular}{ccc} 
Number of beds & Yearly capital expenditure & Expenditure/bed \\
\hline 2 & $\$ 128,571$ & $\$ 64,285.71$ \\
4 & $\$ 185,714$ & $\$ 46,428.57$ \\
6 & $\$ 242,857$ & $\$ 40,476.19$ \\
8 & $\$ 300,000$ & $\$ 37,500.00$ \\
10 & $\$ 357,143$ & $\$ 35,714.29$ \\
12 & $\$ 414,286$ & $\$ 34,523.81$ \\
14 & $\$ 471,429$ & $\$ 33,673.47$ \\
15 & $\$ 500,000$ & $\$ 33,333.33$ \\
16 & $\$ 528,571$ & $\$ 33,035.71$ \\
18 & $\$ 585,714$ & $\$ 32,539.68$ \\
20 & $\$ 642,857$ & $\$ 32,142.86$ \\
22 & $\$ 700,000$ & $\$ 31,818.18$ \\
24 & $\$ 757,143$ & $\$ 31,547.62$ \\
26 & $\$ 814,286$ & $\$ 31,318.68$ \\
\hline
\end{tabular}

507

508

509

510

511

512

513

514

515

516

517

518

519

[2] Almashrafi, A., Vanderbloemen, L., 2016. Quantifying the effect of complications on patient flow, costs and surgical throughputs. BMC MEDICAL INFORMATICS AND DECISION MAKING 16 (1), 1-15.

[3] Anderson, D., Golden, B., Jank, W., Wasil, E., 2012. The impact of hospital utilization on patient readmission rate. Health Care Management Science $15(1), 29-36$.

URL http://dx.doi.org/10.1007/s10729-011-9178-3

[4] Anderson, D., Price, C., Golden, B., Jank, W., Wasil, E., 2011. Examining the discharge practices of surgeons at a large medical center. Health Care Management Science 14 (4), 338-347.

[5] Banks, J., 2005. Discrete-event system simulation, 4th Edition. Pearson Prentice Hall, Upper Saddle River, N.J.

[6] Batchelor, A. M., 2013. United Kingdom: Where Have We Been?, 2013th 


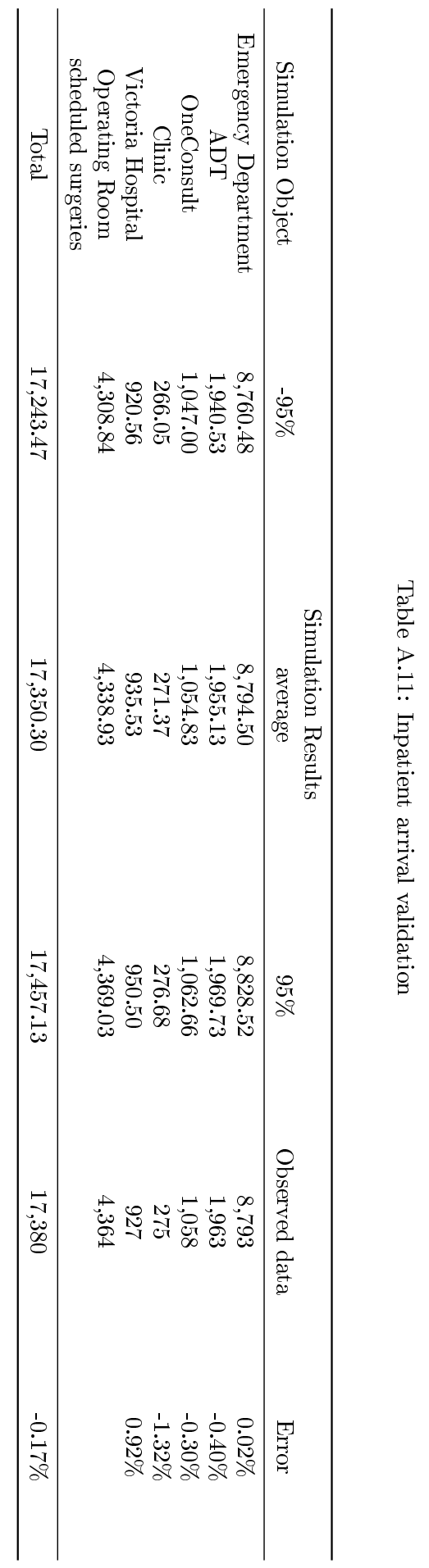


521

524

525

526

527

528

529

530

532

533

534

535

536

537

538

539

540

541

542

543

Edition. Vol. 9781461438663. Springer New York, New York, NY, pp. 8996.

[7] Bountourelis, T., Ulukus, M., Kharoufeh, J., Nabors, S., 2013. The modeling, analysis, and management of intensive care units. In: Denton, B. T. (Ed.), Handbook of Healthcare Operations Management. Vol. 184 of International Series in Operations Research \& Management Science. Springer New York, pp. 153-182.

[8] Brailsford, S. C., Harper, P. R., Patel, B., Pitt, M., 2009. An analysis of the academic literature on simulation and modelling in health care. Journal of Simulation 3, 130-140.

[9] Bretthauer, K. M., Heese, H. S., Pun, H., Coe, E., 2011. Blocking in healthcare operations: A new heuristic and an application. Production and Operations Management 20 (3), 375-391.

URL http://dx.doi.org/10.1111/j.1937-5956.2011.01230.x

[10] CIHI, 2015. Canadian institute for health information. http://yourhealthsystem.cihi.ca.

URL http://yourhealthsystem.cihi.ca

[11] Dobson, G., Lee, H.-H., Pinker, E., 2010. A model of icu bumping. Operations Research 58 (6), 1564-1576.

[12] Doig, C. J., 2013. Canada: Where Have We Been?, 2013th Edition. Vol. 9781461438663. Springer New York, New York, NY, pp. 17-24.

[13] Duguay, C., Chetouane, F., 2007. Modeling and improving emergency department systems using discrete event simulation. SIMULATION 83 (4), $311-320$.

URL http://sim.sagepub.com/content/83/4/311.abstract 
${ }_{545}$ [14] Forsberg, H. H., Aronsson, H., Keller, C., Lindblad, S., 2011. Managing

546 health care decisions and improvement through simulation modeling. Qual-

547 ity Management in Health Care 20(1), 15-29.

${ }_{548}$ [15] Green, L., 2006. Queueing analysis in healthcare. In: Hall, R. W. (Ed.), 549 Patient Flow: Reducing Delay in Healthcare Delivery. Vol. 91 of Interna550 tional Series in Operations Research \& Management Science. Springer US, $551 \quad$ pp. $281-307$.

552 [16] Green, L. V., Soares, J., Giglio, J. F., Green, R. A., 2006. Using queue${ }_{553}$ ing theory to increase the effectiveness of emergency department provider $554 \quad$ staffing. Academic Emergency Medicine 13 (1), 61-68.

$555 \quad$ URL http://dx.doi.org/10.1197/j.aem.2005.07.034

556 [17] Halpern, N. A., Pastores, S. M., 2010. Critical care medicine in the united 557 states 2000-2005: An analysis of bed numbers, occupancy rates, payer mix, 558 and costs. Critical Care Medicine 38, 65-71.

559 [18] Harper, P. R. \& Shahani, A. K., 2002. Modelling for the planning and 560 management of bed capacities in hospitals. The Journal of the Operational $561 \quad$ Research Society 53, 11-18.

562

563

564

565

566

567

568

[19] Hastie, T., Tibshirani, R., Friedman, J. H., 2009. The elements of statistical learning: data mining, inference, and prediction, 2nd Edition. Springer, New York.

[20] Hoyt, J. W., 2013. United States - Private Practice: Where Have We Been?, 2013th Edition. Vol. 9781461438663. Springer New York, New York, NY, pp. $97-100$.

[21] Karnon, J., Stahl, J., Brennan, A., Caro, J. J., Mar, J., Moller, J., 2012. Modeling using discrete event simulation: A report of the ispor-smdm mod- 
570

571

572

573

574

575

576

577

578

579

580

581

582

583

584

585

586

587

588

589

590

591

592

593

eling good research practices task force 4. Medical Decision Making 32 (5), $701-711$.

[22] KC, D. S., Terwiesch, C., 2012. An econometric analysis of patient flows in the cardiac intensive care unit. Manufacturing \& Service Operations Management 14 (1), 50-65.

URL http://pubsonline.inf orms.org/doi/abs/10.1287/msom.1110.0341

[23] Khare, R. K., Powell, E. S., Reinhardt, G., Lucenti, M., 2009. Adding more beds to the emergency department or reducing admitted patient boarding times: Which has a more significant influence on emergency department congestion? Annals of Emergency Medicine 53 (5), 575 - 585.e2.

[24] Kolker, A., 2009. Process modeling of icu patient flow: Effect of daily load leveling of elective surgeries on icu diversion. Journal of Medical Systems $33(1), 27-40$.

[25] Konrad, R., DeSotto, K., Grocela, A., McAuley, P., Wang, J., Lyons, J., Bruin, M., 2013. Modeling the impact of changing patient flow processes in an emergency department: Insights from a computer simulation study. Operations Research for Health Care 2 (4), 66 - 74.

[26] Lakshmi C., Appa Iyer, S., 2013. Application of queueing theory in health care: A literature review. Operations Research for Health Care 2, 25 - 39.

[27] Lane, D. C., Monefeldt, C., Husemann, E., 2003. Client involvement in simulation model building: Hints and insights from a case study in a london hospital. Health Care Management Science 6 (2), 105-116.

[28] LHSC, 2015. Financial statement 2015. online.

URL http://www. Ihsc.on.ca 
595

596

597

598

599

603

604

[29] LHSC, 2016. London health sciences centre facts and stats.

URL www. Ihsc.on.ca

[30] Marmor, Y., Rohleder, T., Cook, D., Huschka, T., Thompson, J., 2013. Recovery bed planning in cardiovascular surgery: a simulation case study. Health Care Management Science 16, 314-327.

[31] Mielczarek, B., Uzialko-Mydlikowska, J., 2012. Application of computer simulation modeling in the health care sector: a survey. SIMULATION $88(2), 197-216$.

[32] Miranda, R. D., Moreno, R., Iapichino, G., 1997. Nine equivalents of nursing manpower use score (nems). Intensive Care Medicine 23 (7), 760-765. URL http://dx.doi.org/10.1007/s001340050406

[33] Mohiuddin, S., Busby, J., Savović, J., Richards, A., Northstone, K., Hollingworth, W., Donovan, J. L., Vasilakis, C., 2017. Patient flow within uk emergency departments: a systematic review of the use of computer simulation modelling methods. BMJ Open 7 (5).

URL http://bmjopen.bmj.com/content/7/5/e015007

[34] NCHS, 2015. Health, united states, 2015. https://www.cdc.gov/nchs/data/hus/hus15.pdf.

URL https://www.cdc.gov/nchs/data/hus/hus15.pdf

[35] Noghani Ardestani, P., 2014. Modeling community care services for alternative level of care (alc) patients: A queuing network approach. mathesis, Systems Science - University of Ottawa, Canada. URL http://search.proquest. com/docview/1520515966? accountid=15115

[36] Noseworthy, T. W., Konopad, E., Shustack, A., Johnston, R., Grace, M. 
619

634

P. E., 1996. Cost accounting of adult intensive care: Methods and human and capital inputs. Critical Care Medicine 24 (7), 1168-1172.

[37] Osorio, C., Bierlaire, M., 2009. An analytic finite capacity queueing network model capturing the propagation of congestion and blocking. European Journal of Operational Research 196 (3), 996 - 1007.

URL http://www.sciencedirect.com/science/article/pii/S0377221708003871

[38] Rau, C.-L., Tsai, P.-F., Liang, S.-F., Tan, J.-C., Syu, H.-C., Jheng, Y.-L., Ciou, T.-S., Jaw, F.-S., 2013. Using discrete-event simulation in strategic capacity planning for an outpatient physical therapy service. Health Care Management Science 16 (4), 352-365.

URL http://dx.doi.org/10.1007/s10729-013-9234-2

[39] Ridge, J., Jones, S., Nielsen, M., Shahani, A., 1998. Capacity planning for intensive care units. European Journal of Operational Research 105 (2), $346-355$.

URL http://www.sciencedirect.com/science/article/pii/S0377221797002403

[40] Rohleder, T. R., Bischak, D. P., Baskin, L. B., 2007. Modeling patient service centers with simulation and system dynamics. Health Care Management Science 10 (1), 1-12.

URL http://dx.doi.org/10.1007/s10729-006-9001-8

[41] Salleh, S., Thokala, P., Brennan, A., Hughes, R., Booth, A., Sep 2017. Simulation modelling in healthcare: An umbrella review of systematic literature reviews. PharmacoEconomics 35 (9), 937-949.

URL https://doi.org/10.1007/s40273-017-0523-3

[42] Schwarz, G., 03 1978. Estimating the dimension of a model. Ann. Statist. $6(2), 461-464$.

URL http://dx.doi.org/10.1214/aos/1176344136 
645

646

[43] Seung-Chul, K., Ira, H., K, Y. K., A, B. T., 2000. Flexible bed allocation and performance in the intensive care unit. Journal of Operations Management 18 (4), $427-443$.

URL http://www.sciencedirect.com/science/article/pii/S0272696300000279

[44] Shahani, A. K., Ridley, S. A., Nielsen, M. S., 2008. Modelling patient flows as an aid to decision making for critical care capacities and organisation. Anaesthesia 63 (10), 1074-1080.

URL http://dx.doi.org/10.1111/j.1365-2044.2008.05577.x

[45] Shukla, N., Lahiri, S., Ceglarek, D., 2015. Pathway variation analysis (pva): Modelling and simulations. Operations Research for Health Care 6, 61 - 77 . URL http://www.sciencedirect.com/science/article/pii/S2211692315300072

[46] Van Berkel, P. T., Blake, J. T., 2007. A comprehensive simulation for wait time reduction and capacity planning applied in general surgery. Health Care Management Science 10 (4), 373-385.

URL http://dx.doi.org/10.1007/s10729-007-9035-6

[47] Zonderland, M. E., Boucherie, R. J., Carter, M. W., Stanford, D. A., 2015. Modeling the effect of short stay units on patient admissions. Operations Research for Health Care 5, $21-27$.

URL http://www.sciencedirect.com/science/article/pii/S2211692315000168 